\title{
Carbon metabolic pathways in phototrophic bacteria and their broader evolutionary implications
}

\author{
Kuo-Hsiang Tang ${ }^{1,2}{ }^{\dagger}$, Yinjie J. Tang ${ }^{3}$ and Robert Eugene Blankenship ${ }^{1,2 *}$ \\ ${ }^{1}$ Department of Biology, Washington University in St. Louis, St. Louis, MO, USA \\ 2 Department of Chemistry, Washington University in St. Louis, St. Louis, MO, USA \\ ${ }^{3}$ Department of Energy, Environment, and Chemical Engineering, Washington University in St. Louis, St. Louis, MO, USA
}

\section{Edited by:}

Thomas E. Hanson, University of

Delaware, USA

Reviewed by:

Thomas E. Hanson, University of

Delaware, USA

Ulrike Kappler, University of

Queensland, Australia

*Correspondence:

Kuo-Hsiang Tang, One Brookings Drive, Campus Box 1137, St. Louis, MO, USA.

e-mail: j.tang@wustl.edu,

Robert Eugene Blankenship, One

Brookings Drive, Campus Box 1137

St. Louis, MO, USA.

e-mail: blankenship@wustl.edu

\section{${ }^{+}$Current Address}

Kuo-Hsiang Tang, Carlson School of

Chemistry and Biochemistry, and

Department of Biology, Clark

University, 950 Main Street,

Worcester, MA 01610, USA.
Photosynthesis is the biological process that converts solar energy to biomass, bioproducts, and biofuel. It is the only major natural solar energy storage mechanism on Earth. To satisfy the increased demand for sustainable energy sources and identify the mechanism of photosynthetic carbon assimilation, which is one of the bottlenecks in photosynthesis, it is essential to understand the process of solar energy storage and associated carbon metabolism in photosynthetic organisms. Researchers have employed physiological studies, microbiological chemistry, enzyme assays, genome sequencing, transcriptomics, and ${ }^{13} \mathrm{C}$-based metabolomics/fluxomics to investigate central carbon metabolism and enzymes that operate in phototrophs. In this report, we review diverse $\mathrm{CO}_{2}$ assimilation pathways, acetate assimilation, carbohydrate catabolism, the tricarboxylic acid cycle and some key, and/or unconventional enzymes in central carbon metabolism of phototrophic microorganisms. We also discuss the reducing equivalent flow during photoautotrophic and photoheterotrophic growth, evolutionary links in the central carbon metabolic network, and correlations between photosynthetic and non-photosynthetic organisms. Considering the metabolic versatility in these fascinating and diverse photosynthetic bacteria, many essential questions in their central carbon metabolism still remain to be addressed.

Keywords: acetate assimilation, autotrophic and anaplerotic $\mathrm{CO}_{2}$ assimilation, biomass and biofuel, ${ }^{13} \mathrm{C}$-based metabolomics, citrate metabolism, photosynthesis, unconventional pathways and enzymes

\section{INTRODUCTION}

Phototrophic bacteria use light as the energy source to produce phosphate bond energy (ATP) and reductants [e.g., NAD(P)H and reduced ferredoxin] through photosynthetic electron transport. Oxygenic phototrophic bacteria, known as cyanobacteria, share similar electron transport pathways with other oxygenic phototrophs (e.g., plants and algae). Photosynthetic electron transport in cyanobacteria proceeds from oxidation of $\mathrm{H}_{2} \mathrm{O}$ in the oxygen evolving complex of Photosystem II (or $\mathrm{H}_{2} \mathrm{O}$ :

Abbreviations: Abbreviations of phototrophic bacteria. Three-letter abbreviation for the generic name of phototrophic bacteria follows the information listed on LPSN (List of Prokaryotic names with Standing in Nomenclature) (http://www.bacterio.cict.fr/index.html).

Other abbreviations. AAPs, aerobic anoxygenic phototrophic Proteobacteria; ACL, ATP citrate lyase; AnAPs, anaerobic anoxygenic phototrophic Proteobacteria; CCL, citryl-CoA lyase; CCS, citryl-CoA synthetase; $(R e) /(S i)-C S,(R e) /(S i)$-citrate synthase; ED, Entner-Doudoroff; EMP, Emden-Meyerhof-Parnas; FAPs, filamentous anoxygenic phototrophs; FBP, fructose 1,6-bisphosphate; Fd, ferredoxin; GAP, D-glyceraldehyde-3-phosphate; Glc, glucose; GSBs, green sulfur bacteria; 3HOP, 3-hydroxypropionate; KDPG, 2-keto-3-deoxy-6-phosphogluconate; $\alpha$-KG, $\alpha$-ketoglutarate; OAA, oxaloacetate; OPP pathway, oxidative pentose phosphate pathway; OTCA/RTCA cycle, oxidative/reductive tricarboxylic acid cycle; PGM, phosphoglycerate mutase; RC, reaction center; R5P, ribose-5-phosphate; RuBisCO, ribulose 1,5-bisphosphate carboxylase/oxygenase. plastoquinone oxidoreductase) through the cytochrome $b_{6 \mathrm{f}}$ complex to $\mathrm{NADP}^{+}$in Photosystem I (plastocyanin: ferredoxin oxidoreductase; Blankenship, 2002). This non-cyclic electron transport is represented in the Z-scheme of photosynthesis. A cyclic electron transport pathway also operates in oxygenic phototrophs during phototrophic growth and synthesizes ATP instead of NADPH (Iwai et al., 2010). Photosynthetic electron transport pathways are different in anoxygenic (non-oxygen evolving) phototrophs, all of which contain either a type II (quinone type) or a type I (Fe-S type) reaction center (RC). Five out of six phyla of photosynthetic bacteria are anoxygenic phototrophs: proteobacteria [anaerobic anoxygenic phototrophic Proteobacteria (AnAPs) and aerobic anoxygenic phototrophic Proteobacteria (AAPs)], green sulfur bacteria (GSBs), filamentous anoxygenic phototrophs (FAPs; or green non-sulfur/gliding bacteria), heliobacteria, and the recently discovered chloroacidobacteria (Blankenship, 2002; Bryant and Frigaard, 2006; Bryant et al., 2007). AAPs, AnAPs, and FAPs contain a type II RC, and GSBs, heliobacteria and chloroacidobacteria have a type I RC. Bacteria with a type II RC operate cyclic electron transport to generate ATP and reverse electron transport to produce $\mathrm{NAD}(\mathrm{P}) \mathrm{H}$. GSBs operate both cyclic and non-cyclic electron transport to make $\mathrm{NAD}(\mathrm{P}) \mathrm{H}$ and ATP, and heliobacteria have been suggested to employ cyclic electron transport (Kramer et al., 1997). 
The energy and reducing equivalents generated from lightinduced electron transport drive diverse carbon metabolic pathways for producing cellular material, bioactive products and biofuel. Additionally, numerous photosynthetic bacteria play essential roles in global carbon, nitrogen, and sulfur cycles, as many of them are known to assimilate nitrogen and/or oxidize sulfide in conjunction with their central carbon and energy metabolisms. Inorganic and organic carbon sources are used for building cellular building blocks of photoautotrophic and photoheterotrophic bacteria, respectively. Cyanobacteria, AnAPs, FAPs, and GSBs can grow autotrophically via a variety of autotrophic $\mathrm{CO}_{2}$ assimilation pathways, while AAPs and heliobacteria are obligate photoheterotrophs. AAPs have been discovered in some ocean surface waters (Kolber et al., 2001) and certain (extreme) ecosystems (Yurkov and Csotonyi, 2009), and may play important roles in global carbon regulation (Kolber et al., 2001). Heliobacteria are the most recently discovered anaerobic anoxygenic phototrophs. Compared to other phototrophic bacteria, heliobacteria have the simplest photosystem (Heinnickel and Golbeck, 2007; Sattley and Blankenship, 2010) and some unique features: they are the only Grampositive phototrophic bacteria in the bacterial phylum Firmicutes (and form heat resistant endospores), and are the only obligate anaerobic photoheterotrophs. All known heliobacteria are active nitrogen fixers and hydrogen producers (Madigan, 2006).

The evolution of eukaryotes has been suggested to have occurred through endosymbiosis (Margulis, 1968; Doolittle, 1998). It has been proposed that the ancestral eukaryotes were anaerobes, and that aerobic $\alpha$-Proteobacteria, which include many AAPs, were the origins of mitochondria of eukaryotes and cyanobacteria were the forerunners of the chloroplast of higher plant cells (Margulis, 1968; Hohmann-Marriott and Blankenship, 2011).

While photosynthetic bacteria have simplified, and sometimes unique, photosystems compared to higher plants and green algae (Blankenship, 2002), their carbon metabolism pathways are rather complex (Figure 1). Previous studies on central carbon metabolism of photosynthetic organisms have suggested that some phototrophic and non-phototrophic organisms use some distinct carbon assimilation and carbon metabolic pathways (Hugler et al., 2011). In this report, we review the studies of key central carbon metabolic pathways, including $\mathrm{CO}_{2}$ and acetate assimilations, carbohydrate catabolism and the tricarboxylic acid (TCA) cycle, and also highlight several essential and/or unconventional enzymes contributing to the critical metabolic pathways in phototrophic bacteria. Some related metabolic pathways and enzymes distributed in non-phototrophic organisms are also discussed. General approaches to investigate the carbon metabolism of phototrophs are presented in Appendix and Table A1 for readers who are interested in further information. Overall, experimental evidence indicates that phototrophic bacteria containing the same type of RC often have distinct central carbon metabolism pathways, suggesting horizontal/lateral gene transfers and late adaptation during the evolution of photosynthesis.

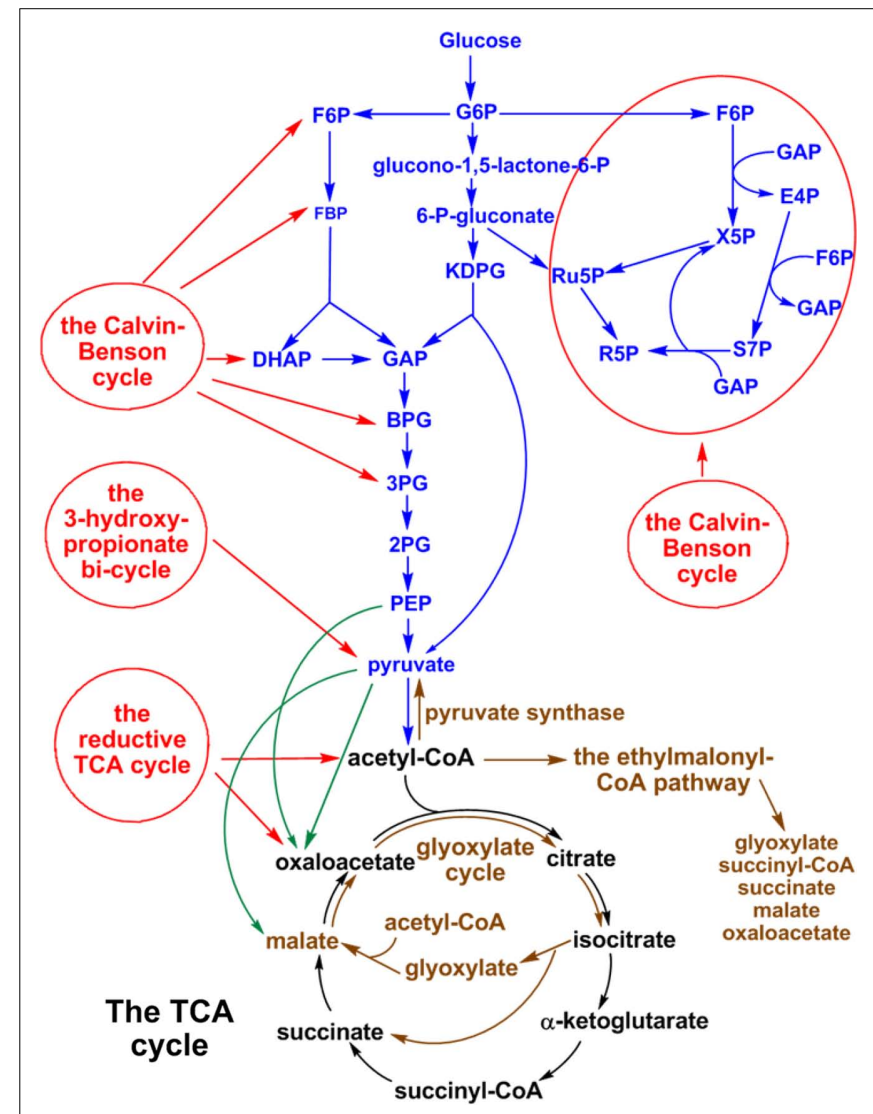

FIGURE 1 | Schematic representation of central carbon metabolism in phototrophic bacteria. The metabolic pathways of autotrophic $\mathrm{CO}_{2}$ fixation (red lines), anaplerotic $\mathrm{CO}_{2}$ assimilation (green lines), carbohydrate metabolism (blue lines), acetate assimilation (brown lines), and the TCA cycle (black lines) in phototrophic bacteria are shown. Some metabolic pathways are employed only in phototrophic bacteria, and others are distributed in phototrophic and non-phototrophic microbes.

\section{RESULTS AND DISCUSSIONS OVERVIEW: THE LIGHT AND DARK REACTIONS IN PHOTOTROPHIC BACTERIA}

No two phyla of phototrophic bacteria have the same metabolic pathways, while some ecological and metabolic features of phototrophic bacteria are correlated with the type of $\mathrm{RC}$ employed. Only the five most characterized phyla of phototrophic bacteria are discussed here. Bacteria with a type II (quinone type) RC (e.g., Proteobacteria and FAPs) are facultative phototrophs (can grow with or without light) and are metabolically versatile (can grow aerobically and anaerobically). Since various types of quinone molecules in the type II RC can freely transport electrons in the membrane, several type II RC bacteria have an active TCA cycle and can perform respiration. Some ancient aerobic $\alpha$-Proteobacteria may have been the ancestors of the mitochondria of modern eukaryotes (Margulis, 1968; Doolittle, 1998).

Bacteria with only a type I (Fe-S type) RC (e.g., GSBs and heliobacteria) are strict anaerobes and metabolic specialists. GSBs direct these reducing equivalents through light-induced electron 
transport to the reductive (reverse) TCA (RTCA) cycle, which is basically the reversal of the oxidative (forward) TCA (OTCA) cycle, for fixing $\mathrm{CO}_{2}$ and producing biomass (Evans et al., 1966a). Heliobacteria have an incomplete RTCA cycle, and can utilize a limited set of carbon sources. Reduced ferredoxins that are electron donors to pyruvate synthase and $\alpha$-ketoglutarate synthase in the RTCA cycle are oxygen-sensitive, which may correlate with GSBs and heliobacteria being strict anaerobes.

Most cyanobacteria utilize the Calvin-Benson cycle for autotrophic $\mathrm{CO}_{2}$ assimilation and can grow photoautotrophically, photomixotrophically, and/or photoheterotrophically. Fermentative growth of cyanobacteria with carbohydrates has also been reported (Stal and Moezelaar, 1997). One group of nitrogenfixing marine cyanobacteria, which do not have Photosystem II, autotrophic carbon assimilation pathways and the TCA cycle, are suggested to be obligate photoheterotrophs (Zehr et al., 2008; Tripp et al., 2010). Anoxygenic phototrophic bacteria are either photoautotrophs or photoheterotrophs. Anoxygenic photoautotrophs operate at least three different autotrophic $\mathrm{CO}_{2}$ fixation pathways, including the Calvin-Benson cycle. As molecular oxygen is a substrate for $\mathrm{RuBisCO}$ (ribulose 1,5-bisphosphate carboxylase/oxygenase) that competes with $\mathrm{CO}_{2}$ in the Calvin-Benson cycle, giving rise to photorespiration. Oxygenic phototrophs contain $\mathrm{CO}_{2}$ concentrating mechanisms and carboxysomes to elevate $\mathrm{CO}_{2}$ concentration at the RuBisCO active site (Kaplan and Reinhold, 1999). Note that some chemolithoautotrophs, such as Thiomicrospira crunogena (Dobrinski et al., 2005) and Thiobacillus neopolitanus (Holthuijzen et al., 1986), contain carboxysomes and appear to employ a carbon concentrating mechanism, so that these adaptations are not exclusively by phototrophic organisms. No such mechanisms have been identified in anoxygenic phototrophs. In response to the intrinsic problem of RuBisCO and carbon fixation via the Calvin-Benson cycle, most anoxygenic bacteria may have either retreated to low oxygen environments and/or adopted different $\mathrm{CO}_{2}$ assimilation pathways (autotrophic or anaplerotic) and various carboxylases for carbon metabolism. Thus, various autotrophic $\mathrm{CO}_{2}$ fixation cycles, as well as some unconventional carbon metabolic pathways, operating in anoxygenic phototrophs are possibly correlated with their special ecological niches, such as high sulfide and low oxygen environments.

\section{CENTRAL CARBON METABOLISM PATHWAYS}

Figure 1 presents a general scheme of central carbon metabolism pathways, including $\mathrm{CO}_{2}$ and acetate assimilation pathways, carbohydrate metabolism and the TCA cycle. Detailed information for each metabolic pathway in five phyla of phototrophic bacteria [e.g., the Proteobacteria (AnAPs and AAPs), GSBs, FAPs, cyanobacteria, and heliobacteria] is elaborated below.

\section{Autotrophic $\mathrm{CO}_{2}$ fixation pathways}

One of the landmarks of photosynthesis is assimilating $\mathrm{CO}_{2}$ autotrophically into cellular material with light, and the most well-known $\mathrm{CO}_{2}$ assimilation pathway is the reductive pentose phosphate (PP) pathway (the Calvin-Benson cycle; Figure 2A; Calvin and Benson, 1948; Bassham et al., 1950; Calvin, 1989). Note that some chemolithoautotrophs also use the Calvin-Benson cycle for carbon fixation (Kusian and Bowien, 1997; Sorokin et al., 2007). Moreover, a complete Calvin-Benson cycle has been found in the genomes of several heterotrophic bacteria (McKinlay and Harwood, 2010), and the roles of key gene products in these bacteria remain to be investigated. In addition to the CalvinBenson cycle, five other autotrophic carbon fixation pathways have also been identified (Ensign, 2006; Thauer, 2007; Raven, 2009; Berg et al., 2010; Hugler and Sievert, 2011), including the RTCA cycle (the Arnon-Buchanan-Evans cycle; Figure 2B), the 3-hydroxypropionate (3HOP) bi-cycle (Figure 2C), the 3hydroxypropionate/4-hydroxybutyrate $(3 \mathrm{HOP} / 4 \mathrm{HOB})$ cycle, the dicarboxylate $/ 4 \mathrm{HOB}$ cycle, and the reductive acetyl-CoA pathway (the Wood-Ljungdahl pathway). The $3 \mathrm{HOP} / 4 \mathrm{HOB}$ cycle (Berg et al., 2007), which is similar to the 3HOP bi-cycle and uses the same carbon assimilation enzymes (e.g., acetyl-CoA carboxylase and propionyl-CoA carboxylase), the dicarboxylate/4HOB cycle (Huber et al., 2008), and the reductive acetyl-CoA pathway (Ljungdahl, 1986; Wood, 1991) have not yet been reported in phototrophs and are not discussed further here.

Among these autotrophic carbon fixation pathways, cyanobacteria and AnAPs use the Calvin-Benson cycle (Tabita, 1995; Blankenship, 2002). GSBs use the RTCA cycle (Evans et al., 1966a,b; Buchanan and Arnon, 1990) and the FAP bacterium Chloroflexus aurantiacus utilizes the 3HOP bi-cycle (Holo, 1989; Strauss and Fuchs, 1993; Herter et al., 2002; Zarzycki et al., 2009). Several Oscillochloridaceae strains in FAPs have been reported to use the Calvin-Benson cycle, instead of the $3 \mathrm{HOP}$ bi-cycle, and those strains also have a branched TCA cycle (Berg et al., 2005; Table 1). The RTCA cycle is also distributed in many non-phototrophic bacteria (Hugler and Sievert, 2011), including Hydrogenobacter thermophilus (Shiba et al., 1985) and some members of the $\varepsilon$ Proteobacteria (Hugler et al., 2005, 2007; Takai et al., 2005). While biochemical analyses indicate that certain enzymes in the RTCA cycle are oxygen-sensitive, several autotrophic microbes (such as H. thermophilus and Aquifex aeolicus) that employ the RTCA cycle are not strict anaerobes and can grow well aerobically (Kawasumi et al., 1984; Pandelia et al., 2011). The Calvin-Benson cycle and the $3 \mathrm{HOP}$ bi-cycle can operate in both aerobic and anaerobic conditions, although oxygen is the substrate for RuBisCO that competes with $\mathrm{CO}_{2}$ in the Calvin-Benson cycle.

No autotrophic carbon assimilation pathways have been reported in AAPs (Yurkov and Beatty, 1998; Fuchs et al., 2007; Swingley et al., 2007), heliobacteria (Madigan, 2006), and the genus Roseiflexus in FAPs (Hanada et al., 2002). The genus Roseiflexus in FAPs has been suggested to be photoheterotrophic and not photoautotrophic (Hanada et al., 2002), although genes encoding the $3 \mathrm{HOP}$ bi-cycle have been found in the genome (Klatt et al., 2007). Further, preliminary studies indicate that the most recently identified photosynthetic bacterium Candidatus Chloracidobacterium (Cab.) thermophilum (Bryant et al., 2007), which is a member of the sixth photosynthetic bacteria phylum the Acidobacteria, is perhaps also a photoheterotroph, due to the lack of evidence supporting autotrophic carbon assimilation and growth.

Many metabolites, intermediates or products produced by these autotrophic carbon fixation pathways are essential for building cellular material. The Calvin-Benson cycle synthesizes 3phosphoglycerate (3PG) and sugar phosphates (including triose-, 

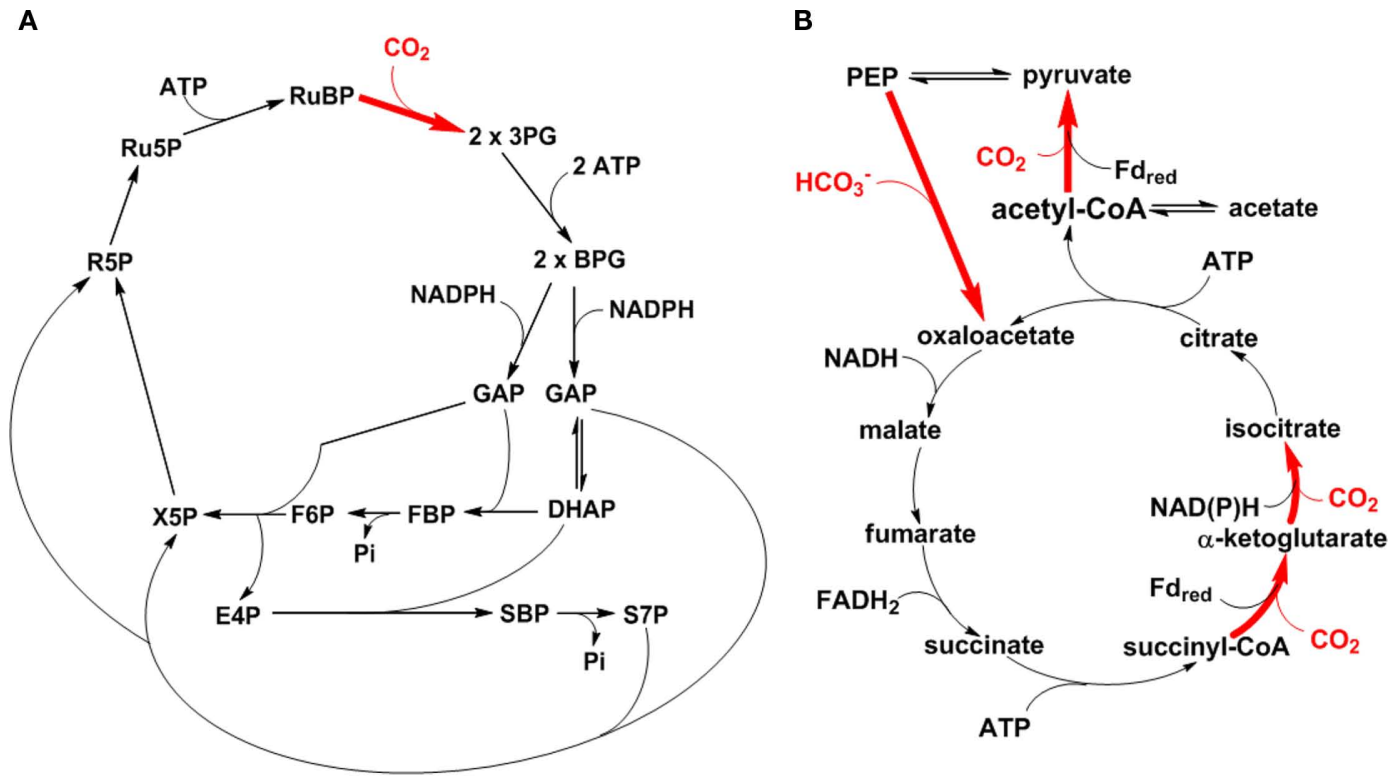

C

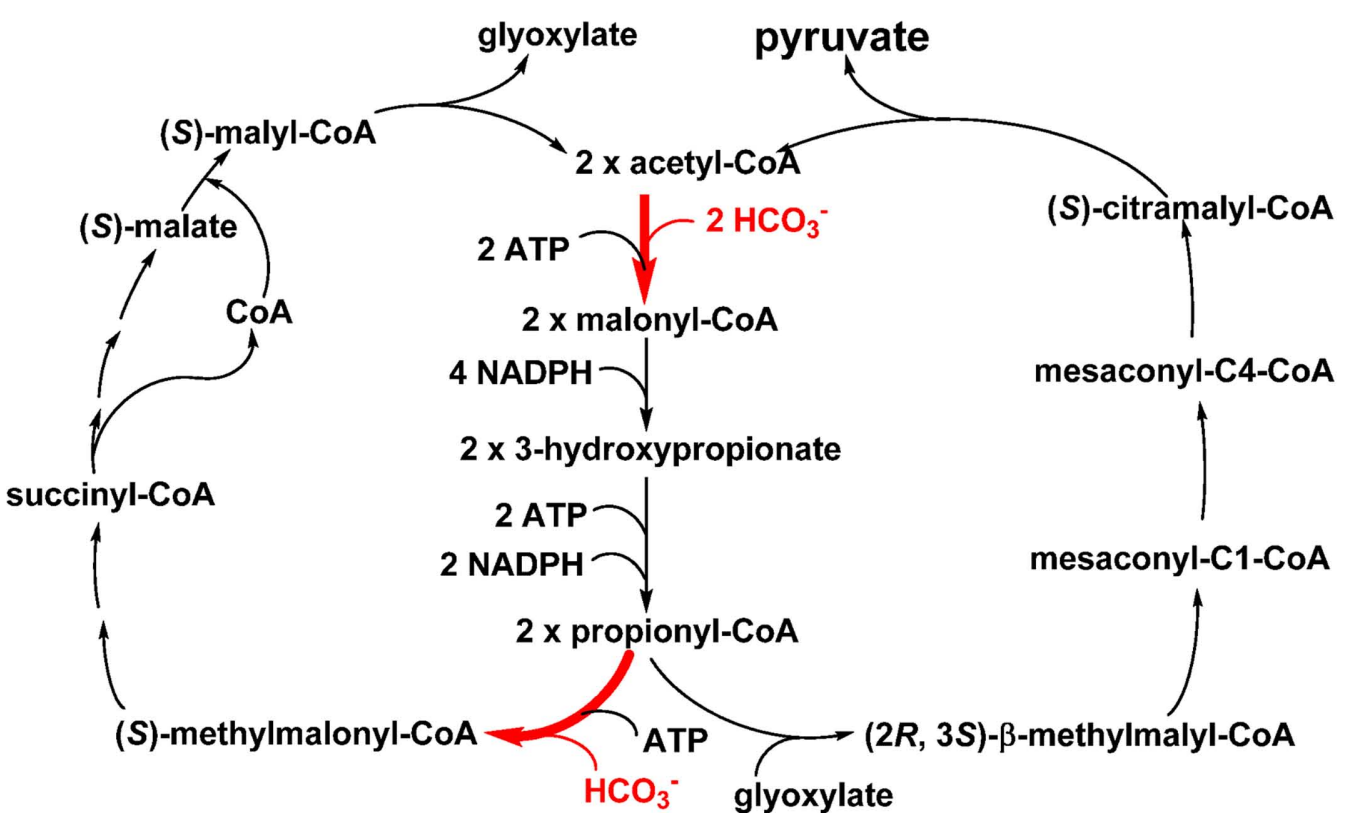

FIGURE 2 | Autotrophic $\mathbf{C O}_{\mathbf{2}}$ fixation pathways in phototrophic organisms. The $\mathrm{CO}_{2}$ assimilation steps in the Calvin-Benson cycle (A), reductive TCA (RTCA) cycle (B) and 3-hydroxypropionate bi-cycle $\mathbf{( C )}$ are shown in bold and colored red. Reactions catalyzed by PEP carboxylase (i.e., the enzyme for anaplerotic $\mathrm{CO}_{2}$ assimilation) and pyruvate synthase are included in the RTCA cycle (B). Participations or consumption of ATP and reducing equivalents are shown.

tetrose-, pentose-, hexose-, and heptose phosphates), and all of the other autotrophic carbon fixation pathways produce or regenerate acetyl-CoA, and several of them also generate pyruvate, phosphoenolpyruvate (PEP), oxaloacetate (OAA), glyoxylate, succinyl-CoA, and/or $\alpha$-ketoglutarate (Table 2). All of these metabolites are essential for the central carbon metabolism of microorganisms.

\section{Acetate assimilation}

Many AAPs, AnAPs, FAPs, GSBs, and heliobacteria have been reported to grow heterotrophically or mixotrophically (in the presence of $\mathrm{CO}_{2}$ ) on acetate with three acetate assimilation mechanisms: the (oxidative) glyoxylate cycle (Figure 3A), pyruvate synthase (Figure 3B), and the ethylmalonyl-CoA pathway (Figure $3 \mathrm{C}$ ). The (oxidative) glyoxylate cycle and the 
Table 1 | The carbon assimilation pathways reported in phototrophic bacteria.

\begin{tabular}{|c|c|c|c|c|c|c|}
\hline & AnAPs & AAPs & FAPs & GSBs & Heliobacteria & Cyanobacteria \\
\hline \multicolumn{7}{|c|}{ AUTOTROPHIC $\mathrm{CO}_{2}$ FIXATION PATHWAYS AND ANAPLEROTIC $\mathrm{CO}_{2}$ ASSIMILATIONS } \\
\hline The Calvin-Benson cycle & $\sqrt{ }$ & & $\sqrt{ }$ & & & $\sqrt{ }$ \\
\hline The 3-hydroxypropionate bi-cycle & & & $\sqrt{ }$ & & & \\
\hline Anaplerotic $\mathrm{CO}_{2}$ assimilations & $\sqrt{ }$ & $\sqrt{ }$ & $\sqrt{ }$ & $\sqrt{ }$ & $\sqrt{ }$ & $\sqrt{ }$ \\
\hline Pyruvate synthase & & & $\sqrt{ }$ & $\sqrt{ }$ & $\sqrt{ }$ & \\
\hline The ethylmalonyl-CoA pathway & $\sqrt{ }$ & $\sqrt{ }$ & & & & \\
\hline
\end{tabular}

AnAPs, anaerobic anoxygenic phototrophic Proteobacteria; AAPs, aerobic anoxygenic phototrophic Proteobacteria; FAPs, filamentous anoxygenic phototrophs; GSBs, green sulfur bacteria.

Table 2 | Metabolites generated from $\mathrm{CO}_{2}$ and acetate assimilation pathways for producing cellular material in phototrophic organisms.

\begin{tabular}{|c|c|c|c|c|c|c|c|c|c|}
\hline Pathways & $\begin{array}{l}\text { 3PG, triose } \\
\text { and sugar } \\
\text { phosphate }\end{array}$ & Acetyl-CoA & Pyruvate & PEP & OAA & malate & Glyoxylate & $\begin{array}{l}\text { Succinyl-CoA/ } \\
\text { succinate }\end{array}$ & $\alpha-K G$ \\
\hline
\end{tabular}

\begin{tabular}{|c|c|c|c|c|c|c|c|c|}
\hline \multicolumn{9}{|c|}{ AUTOTROPHIC $\mathrm{CO}_{2}$ FIXATION PATHWAYS AND ANAPLEROTIC $\mathrm{CO}_{2}$ ASSIMILATIONS } \\
\hline The Calvin-Benson cycle & & & & & & & & \\
\hline The reductive TCA cycle & $\sqrt{ }$ & $\sqrt{ }$ & $\sqrt{ }$ & $\sqrt{ }$ & $\sqrt{ }$ & & $\sqrt{ }$ & $\sqrt{ }$ \\
\hline Anaplerotic $\mathrm{CO}_{2}$ assimilations & & $\sqrt{ }$ & $\sqrt{ }$ & $\sqrt{ }$ & $\sqrt{ }$ & & & \\
\hline \multicolumn{9}{|c|}{ ACETATE ASSIMILATION PATHWAYS } \\
\hline The (oxidative) glyoxylate cycle & & & & $\sqrt{ }$ & $\sqrt{ }$ & $\sqrt{ }$ & $\sqrt{ }$ & \\
\hline
\end{tabular}

3PG, 3-phosphoglycerate; PEP, phosphoenolpyruvate; OAA, oxaloacetate; and $\alpha-K G, \alpha-k e t o g l u t a r a t e$.

ethylmalonyl-CoA pathway can replenish the metabolites in the TCA cycle. Pyruvate synthase and the ethylmalonyl-CoA pathway assimilate both acetate and inorganic carbon $\left(\mathrm{CO}_{2} / \mathrm{HCO}_{3}^{-}\right)$. Distributions of the acetate assimilation pathways in phototrophic bacteria are listed in Table 1.

The (oxidative) glyoxylate cycle. The (oxidative) glyoxylate cycle, discovered more than 50 years ago by Kornberg and Krebs (1957), produces four-carbon units (malate, OAA, and succinate) by assembling two acetyl-CoA molecules (Figure 3A). It is essential not only to convert acetate, lipids and some amino acids to carbohydrates, but also to other central biosynthetic precursors in the TCA cycle (anaplerotic function). The glyoxylate cycle has also been found in plants, some (non-phototrophic) bacteria, archaea, protists, fungi, and nematodes. The glyoxylate cycle is active and has been suggested to channel excess carbon flow away from the branched TCA cycle during mixotrophic and heterotrophic, but not autotrophic, growth of the cyanobacterium Synechocystis sp. PCC 6803 (Yang et al., 2002; Shastri and Morgan, 2005).

Some AnAPs either operate an active glyoxylate cycle (e.g., Rps. palustris; McKinlay and Harwood, 2011) or have genes in the pathway identified (e.g., Rhodospirillum centenum, Rps. palustris and Rba. capsulatus; Oda et al., 2008; Lu et al., 2010; Strnad et al., 2010), whereas other AnAPs apparently lack essential genes/enzymes in the pathway (e.g., Rubrivivax gelatinosus, Rba. Sphaeroides, and Rhodospirillum rubrum; Albers and Gottschalk, 1976; Lim et al., 2009). Genes in the glyoxylate cycle have also been identified in the genome of several FAPs (Cfl. aurantiacus, Cfl. aggregans, Chloroflexus sp. Y-400-fl, Roseiflexus castenholzii and Roseiflexus sp. RS-1; Tang et al., 2011). GSBs, AAPs, and heliobacteria do not have an active glyoxylate cycle, and use alternative acetate assimilation pathways (discussed below).

Pyruvate synthase. With no active glyoxylate cycle reported, GSBs and heliobacteria use pyruvate synthase (or pyruvate: ferredoxin oxidoreductase) for acetate assimilation. Pyruvate synthase converts acetyl-CoA to pyruvate and can assimilate both acetate (i.e., acetyl-CoA) and $\mathrm{CO}_{2}$ (Figure 3B). The catalysis requires reduced ferredoxin and thus only anaerobic anoxygenic bacteria operate pyruvate synthase. Pyruvate synthase synthesizes pyruvate from acetyl-CoA produced through acetate uptake and the RTCA cycle during mixotrophic growth of GSBs (Evans et al., 1966a; Feng et al., 2010b; Tang and Blankenship, 2010). $\mathrm{CO}_{2}$ is required for the growth of heliobacteria in the medium containing acetate as the only organic carbon source (Madigan, 2006; Tang et al., 2010b), and the supplemented $\mathrm{CO}_{2}$ is required not only for anaplerotic 


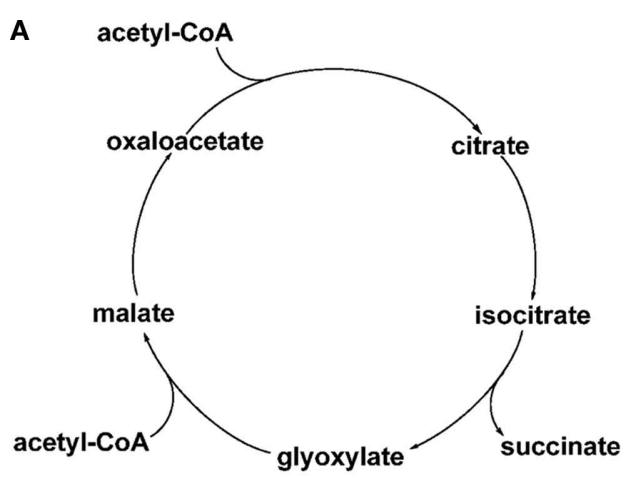

C

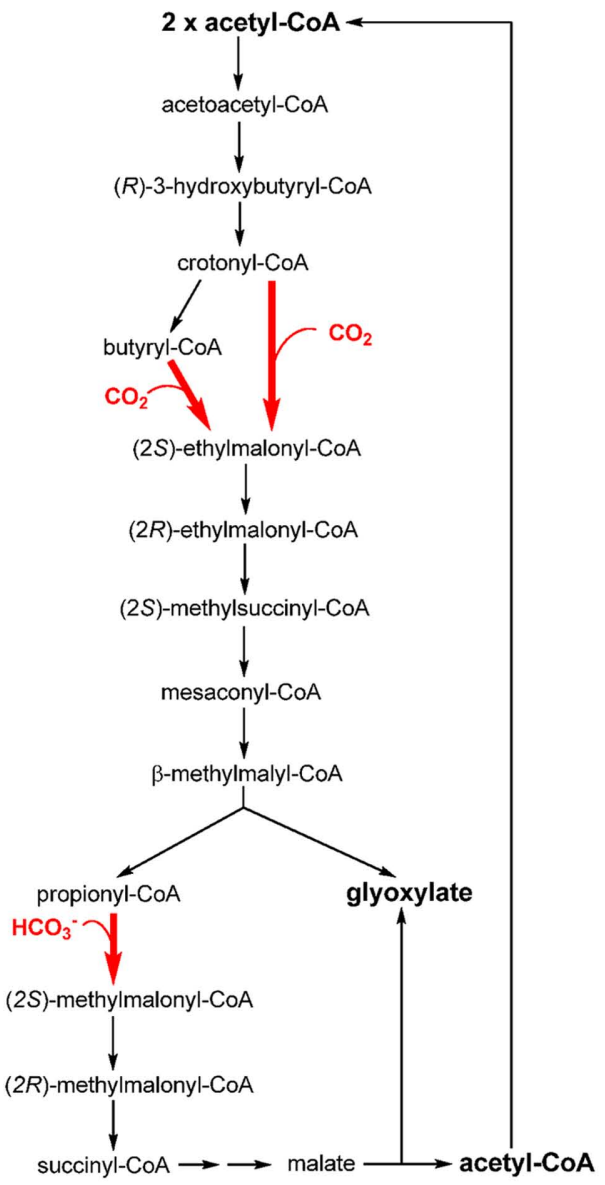

Methylobacterium extorquens AM1

FIGURE 3 | Acetate assimilation pathways. Three acetate assimilation pathways, the (oxidative) glyoxylate cycle (A), the reaction catalyzed by pyruvate synthase (B) and the ethylmalonyl-CoA pathway (C), are shown. All of the acetate assimilation pathways may directly or indirectly synthesize

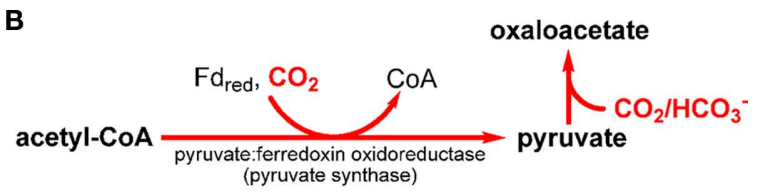

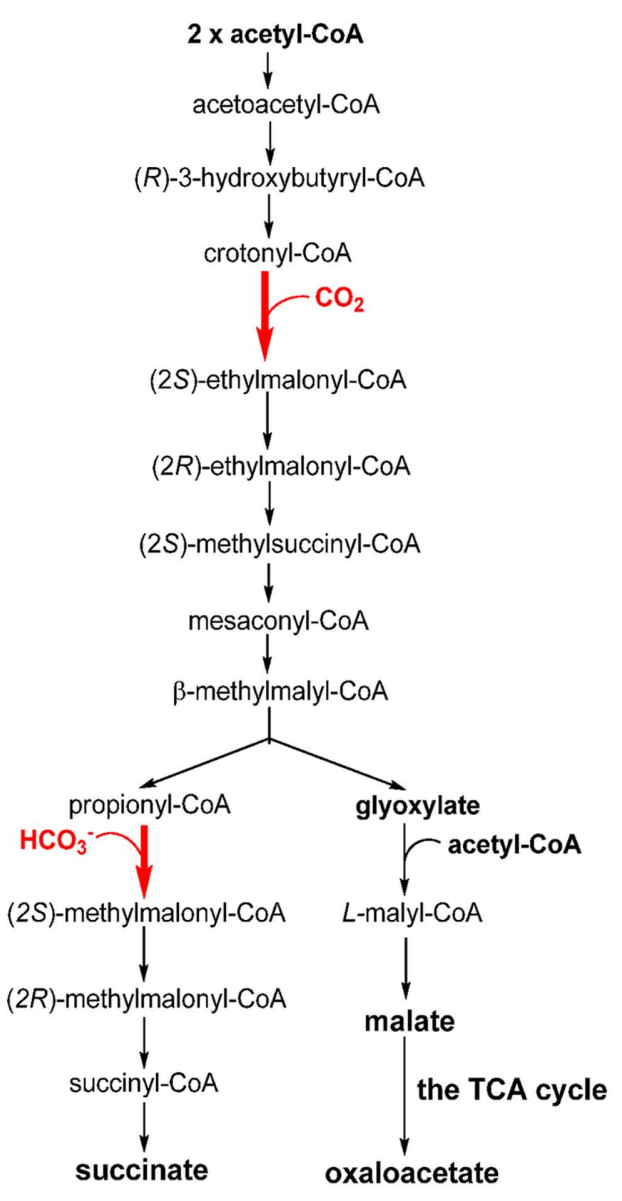

Rhodobacter sphaeroides

oxaloacetate. The $\mathrm{CO}_{2}$ assimilation steps in the pathway/cycle are shown in bold and colored red. Different ethylmalonyl-CoA pathways have been reported in Methylobacterium extorquens AM1 [(C), left] and Rhodobacter sphaeroides [(C), right].

$\mathrm{CO}_{2}$ assimilation, but also the generation of pyruvate catalyzed by pyruvate synthase (Pickett et al., 1994; Tang et al., 2010a,b).

The ethylmalonyl-CoA pathway. The ethylmalonyl-CoA pathway is responsible for producing glyoxylate in some (chemotrophic) methylotrophs (e.g., Methylobacterium extorquens AM1; Korotkova et al., 2002; Peyraud et al., 2009; Smejkalova et al., 2010; Figure 3C, left; net reaction: acetyl-CoA $+2 \mathrm{CO}_{2} \rightarrow 2$ glyoxylate $+\mathrm{CoA}+\mathrm{H}^{+}$), and has also been proposed in some actinobacteria (Erb et al., 2009). The produced glyoxylate can be 
further converted to PEP via the serine pathway, which assimilates one carbon unit through $N_{5}, N_{10}$-methylene-tetrahydrofolate (Erb et al., 2007). The ethylmalonyl-CoA pathway has also been identified in the AnAP bacterium Rhodobacter sphaeroides (Alber et al., 2006; Erb et al., 2007) and is proposed in several AnAPs (Albers and Gottschalk, 1976; Ivanovsky et al., 1997; Alber et al., 2006; Erb et al., 2009). In contrast to the ethylmalonyl-CoA pathway reported in $M$. extorquens AM1, Rba. sphaeroides condenses glyoxylate with acetyl-CoA to produce malyl-CoA, which is further hydrolyzed to malate and CoA (Figure 3C, right).

Acetate can support the phototrophic and chemotrophic (in darkness) growth of several AAPs (Shiba and Simidu, 1982; Shiba and Harashima, 1986; Shiba, 1991; Yurkov et al., 1996; Koblizek et al., 2003; Biebl et al., 2005, 2006). The mechanism of acetate assimilation remains to be understood in these organisms because some AAPs do not have an active glyoxylate cycle and no AAPs have pyruvate synthase identified. Thus, acetategrown AAPs require alternative pathways to produce OAA, which is required for producing biomass and building blocks of cells. Note that the ethylmalonyl-CoA pathway has been recently suggested to be employed by AAPs (Alber et al., 2006). It is of interest to verify if the proposed ethylmalonyl-CoA pathway is active in AAPs, and whether it plays an important role in $\mathrm{CO}_{2}$ assimilation by AAPs.

\section{Reducing equivalent flow in photoautotrophs and photoheterotrophs} Photosynthesis generates reducing equivalents through lightinduced electron transport. In photoautotrophic bacteria, channeling reducing equivalents to autotrophic $\mathrm{CO}_{2}$ fixation pathways is essential when phototrophs cannot respire. For example, GSBs are obligate photoautotrophs and cannot grow heterotrophically and in darkness. The reducing equivalents generated from photosynthetic electron transport in the type I (Fe-S type) RC of GSBs can be utilized for $\mathrm{CO}_{2}$ assimilation (via the RTCA cycle) and other types of cellular metabolism during phototrophic growth. A similar scenario can be found in chloroplasts in photosynthetic eukaryotes, NADPH produced from non-cyclic electron transport is employed for assimilating $\mathrm{CO}_{2}$ via the Calvin-Benson cycle. Alternatively, heliobacteria, the other anaerobic anoxygenic bacteria with a type I RC, do not have an autotrophic $\mathrm{CO}_{2}$ fixation mechanism. The reducing equivalents generated from their photosynthetic electron transport are utilized to reduce organic and inorganic molecules in cells, and all known heliobacterial species are active nitrogen fixers and hydrogen producers (Madigan, 2006).

In contrast to GSBs and heliobacteria, AnAPs can grow both photoautotrophically and photoheterotrophically. Unlike the wild-type, RuBisCO-, and phosphoribulokinase (PRK)-knockout $R b a$. sphaeroides mutants require dimethyl sulfoxide as an alternative external electron recipient to accept (excess) reducing equivalents produced during photoheterotrophic growth (Hallenbeck et al., 1990a,b; Falcone and Tabita, 1991). Also, RuBisCOknockout Rsp. rubrum and Rba. sphaeroides can grow photoheterotrophically under nitrogen fixation conditions (Joshi and Tabita, 1996) and produce abundant $\mathrm{H}_{2}$ presumably from utilizing excess reducing equivalents. Recent metabolic flux analyses on the AnAP bacterium Rhodopseudomonas palustris also suggest that the Calvin-Benson cycle is not only assimilating $\mathrm{CO}_{2}$ and producing biomass during photoautotrophic growth, but is also accepting reducing equivalents during photoheterotrophic growth (e.g., when the Calvin-Benson cycle becomes expendable; McKinlay and Harwood, 2010). Furthermore, the choice of the pathway for assimilating organic compounds during photoheterotrophic growth is also important (Laguna et al., 2011). During photoheterotrophic growth, Rps. palustris uses reducing equivalents to produce hydrogen rather than assimilate carbon (McKinlay and Harwood, 2011) and Rba. sphaeroides directs most of the reducing equivalents to assimilate acetate using the ethylmalonyl-CoA pathway and therefore hydrogen production decreases (Laguna et al., 2011). These studies are consistent with observations that RuBisCO-knockout Rba. sphaeroides can grow photolithoautotrophically using thiosulfate or sulfide, which is not as a potent reductant as $\mathrm{H}_{2}$, as the electron source and thus consuming the excess reducing equivalents produced by photosynthesis is less essential (Wang et al., 1993), although the pathway for assimilating $\mathrm{CO}_{2}$ in these experiments is not clear. Alternative pathways for removing excess reducing equivalents are utilized by certain AAPs during photoheterotrophic growth; for example, nitrate reduction to ammonium by Roseobacter denitrificans (Shiba, 1991; Tang et al., 2009a).

Several heterocystous and non-heterocystous cyanobacteria are known to be active nitrogen fixers and hydrogen producers (Summers et al., 1995; Chen et al., 1998; Bandyopadhyay et al., 2010; Li et al., 2010). The non-heterocystous cyanobacterium Cyanothece sp. ATCC 51142, which can produce hydrogen aerobically (Bandyopadhyay et al., 2010), guides reducing equivalents to reduce nitrate to ammonium during photoheterotrophic growth with glycerol (Feng et al., 2010a).

\section{Anaplerotic $\mathrm{CO}_{2}$ assimilations}

Anaplerotic reactions replenish the intermediates in a metabolic pathway. Anaplerotic $\mathrm{CO}_{2}$ assimilations are those that replenish OAA or malate for replenishing the TCA cycle, and are important to synthesize cellular building blocks. Anaplerotic $\mathrm{CO}_{2}$ assimilations cannot serve as an autotrophic $\mathrm{CO}_{2}$ fixation pathway because they require organic substrates that are not subsequently produced from the incorporation of $\mathrm{CO}_{2}$. Four enzymes catalyzing anaplerotic $\mathrm{CO}_{2}$ assimilation have been reported: pyruvate carboxylase, phosphoenolpyruvate (PEP) carboxylase, PEP carboxykinase, and malic enzyme (Figure 4). Anaplerotic $\mathrm{CO}_{2}$ assimilations have been reported in all types of phototrophic bacteria. Among these, AnAPs, AAPs have an active complete OTCA cycle and can regenerate $\mathrm{OAA}$, and can also replenish OAA via anaplerotic $\mathrm{CO}_{2}$ assimilations (Yurkov and Beatty, 1998; Furch et al., 2009; Tang et al., 2009a) and the glyoxylate cycle and/or the ethylmalonylCoA pathway (Albers and Gottschalk, 1976; Alber et al., 2006; Erb et al., 2007) to produce OAA. Alternatively, anaplerotic $\mathrm{CO}_{2}$ assimilations are essential for the growth of heliobacteria, cyanobacteria, and GSBs, all of which can only use anaplerotic $\mathrm{CO}_{2}$ assimilations to replenish OAA.

Heliobacteria. The activity of PEP carboxykinase has been reported in heliobacteria (Pickett et al., 1994; Tang et al., 2010b). In 


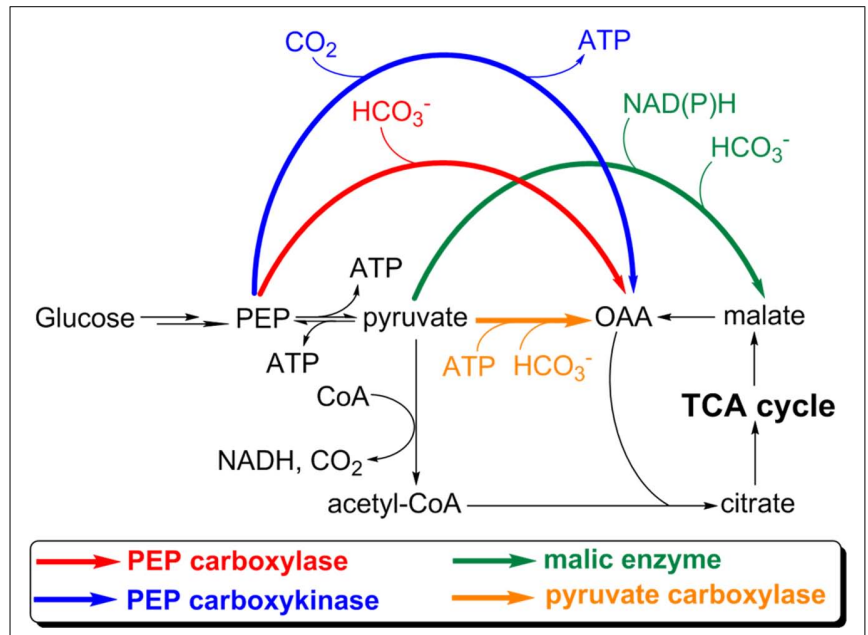

FIGURE 4 | Anaplerotic $\mathbf{C O}_{2}$ assimilation reactions. The $\mathrm{CO}_{2}$-anaplerotic reactions catalyzed by pyruvate carboxylase, PEP carboxylase, PEP carboxykinase, and malic enzyme are shown. Participations or consumption of ATP and reducing equivalents are presented. Abbreviation: PEP, phosphoenolpyruvate; OAA, oxaloacetate.

contrast to AnAPs, AAPs, and FAPs, heliobacteria have an incomplete OTCA cycle (Tang et al., 2010a), which cannot regenerate OAA, and do not have the glyoxylate cycle and ethylmalonyl-CoA pathway (Table 1). As a result, the anaplerotic $\mathrm{CO}_{2}$ assimilation is the only approach to synthesize OAA and is essential for the growth of heliobacteria, consistent with high flux in the anaplerotic $\mathrm{CO}_{2}$ assimilation in heliobacteria (Tang et al., 2010a).

Cyanobacteria and GSBs. Active anaplerotic $\mathrm{CO}_{2}$ assimilations have been identified in GSBs (Evans et al., 1966a; Sirevag, 1995; Feng et al., 2010b; Tang and Blankenship, 2010) and cyanobacteria (Neuera and Bothe, 1983; Owttrim and Colman, 1988; Zhang et al., 2004; Stockel et al., 2011). Cyanobacteria have a branched TCA cycle (enzymes that catalyze the interconversion of $\alpha$-ketoglutarate and succinate are absent) and cannot regenerate OAA (Stanier and Cohen-Bazire, 1977). An active glyoxylate cycle in Synechocystis sp. PCC 6803 has been reported (Yang et al., 2002; Shastri and Morgan, 2005), although key genes in the glyoxylate cycle are absent in the genomes of most cyanobacteria. GSBs require OAA to initiate the RTCA cycle and do not have the glyoxylate cycle and ethylmalonylCoA pathway. Although GSBs can produce OAA via ATP citrate lyase (ACL) in the RTCA cycle (see Enzymes that dissimilate citrate), OAA needs to be replenished by anaplerotic $\mathrm{CO}_{2}$ assimilations if large amounts of $\alpha$-ketoglutarate and other metabolites are pulled out of the cycle for nitrogen assimilation and other cellular metabolism. As a result, cyanobacteria (if the glyoxylate cycle is absent) and GSBs can only replenish OAA through anaplerotic $\mathrm{CO}_{2}$ assimilations. It has been shown that malic enzyme is essential for optimal photoautotrophic growth of cyanobacteria (Bricker et al., 2004).

Altogether, active anaplerotic reactions are essential not only for photoheterotrophs (heliobacteria), but are also for the photoautotrophs (cyanobacteria and GSBs). Even though anaplerotic $\mathrm{CO}_{2}$ assimilations cannot support phototrophic growth in the way
Table 3 | The carbohydrate catabolic pathways reported in phototrophic bacteria.

\begin{tabular}{lllll}
\hline & $\begin{array}{l}\text { The EMP } \\
\text { pathway }\end{array}$ & $\begin{array}{l}\text { The ED } \\
\text { pathway }\end{array}$ & $\begin{array}{l}\text { The oxidative } \\
\text { pentose } \\
\text { phosphate } \\
\text { pathway }\end{array}$ & $\begin{array}{l}\text { The non-oxidative } \\
\text { pentose } \\
\text { phosphate } \\
\text { pathway }\end{array}$ \\
& & & - & $\sqrt{ }$ \\
AnAPs & $\sqrt{ }$ & $\sqrt{ }$ & - & $\sqrt{ }$ \\
AAPs & - & $\sqrt{ }$ & - & $\sqrt{ }$ \\
FAPs & $\sqrt{ }$ & - & $\sqrt{ }$ & $\sqrt{ }$ \\
GSBs & - & - & - & $\sqrt{ }$ \\
Heliobacteria & $\sqrt{ }$ & - & - & $\sqrt{ }$ \\
Cyanobacteria & $\sqrt{ }$ & - & $\sqrt{ }$ &
\end{tabular}

-: Not shown in the experimental evidences or/and not present in the genomes. aThe non-oxidative pentose phosphate pathway is unequal to the reductive pentose phosphate pathway (or the Calvin-Benson cycle), as illustrated in Figures 2 and 5.

that the autotrophic carbon fixation pathways support photoautotrophic growth because they require pre-existing/endogenous organic compounds that are not produced by the pathway, anaplerotic $\mathrm{CO}_{2}$ assimilations are nonetheless crucial for the cell growth of phototrophic organisms.

\section{Carbohydrate metabolism}

Most chemoheterotrophic organisms use carbohydrates as carbon sources to build up cellular material and provide reductants. GSBs are the only group of phototrophic bacteria that do not apparently grow on carbohydrates as sole carbon sources (Table 3 ). Three carbohydrate catabolic pathways in photosynthetic organisms are known: the Emden-Meyerhof-Parnas (EMP) pathway (glycolysis), Entner-Doudoroff (ED) pathway, and PP pathway (also called the phosphogluconate pathway), which includes the oxidative PP (OPP) and non-OPP pathways (Figure 5A). The EMP pathway and the ED pathway convert one molecule of glucose into two molecules of pyruvate, although different courses are employed by these two pathways. Regulation of these two pathways provides flexibility for energy generation and bypasses bottlenecks for glucose oxidation (Selig et al., 1997). For instance, glucose oxidation through the ED pathway can avoid the phosphofructokinase reaction [fructose 6-phosphate $(\mathrm{F} 6 \mathrm{P}) \rightarrow$ fructose 2,6-bisphosphate (FBP)], which is one of the irreversible and ratedetermining steps in the EMP pathway (Nelson and Cox, 2008). Only the OPP pathway, not the non-OPP pathway, can produce reducing equivalents. Note that the non-OPP pathway is not the same as the reductive PP pathway (or the Calvin-Benson cycle). $\mathrm{R} 5 \mathrm{P}$ produced via the PP pathway is a precursor for the biosynthesis of nucleic acids, ATP, histidine, and coenzymes. Net energy output and reductant production for the three glucose catabolic pathways are: 2 ATP and 2 NADH via the EMP pathway, 2 NADPH via the (oxidative) PP pathway, and $1 \mathrm{NADPH}$ (the reaction that generates the first NADPH in the OPP pathway is part of the ED pathway), 1 ATP and 1 NADH via the ED pathway. Moreover, ATP can be also generated in the oxidative pentose phosphate pathway. depending on the flux mode considered (Kruger and von Schaewen, 2003). 
A

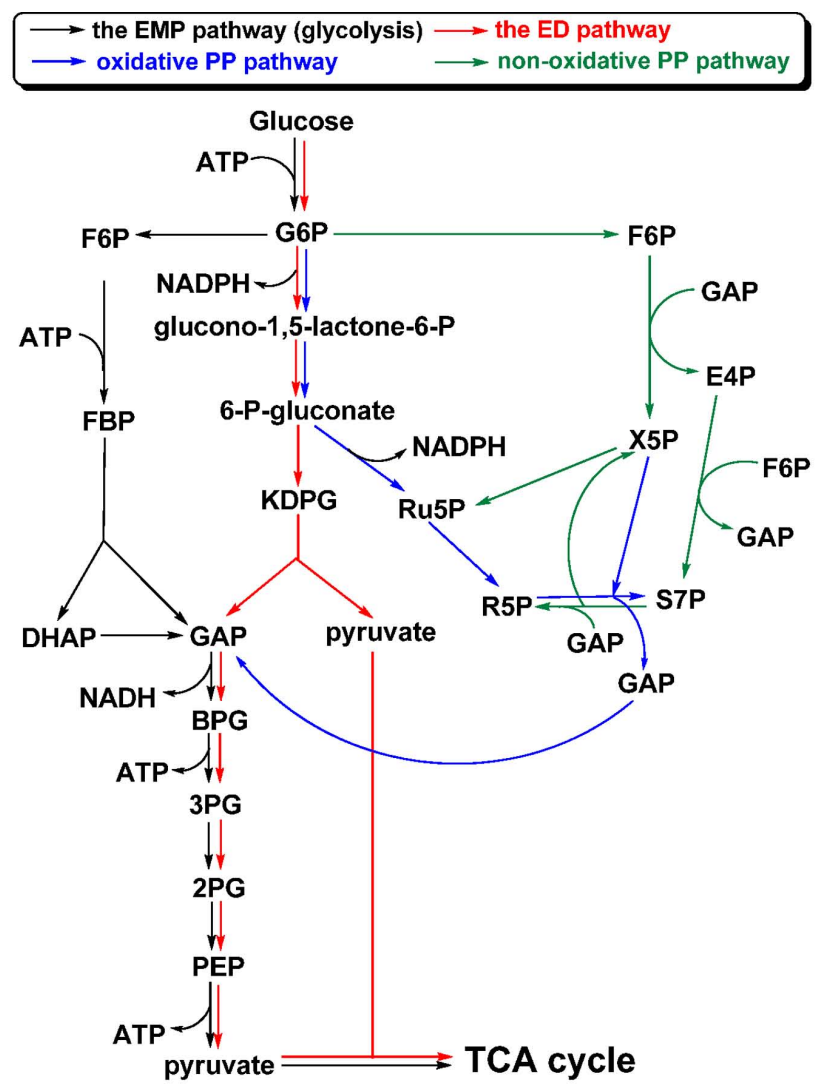

B<smiles>CC(OP)C(O)C(O)C(=O)COP</smiles>

fructose 1,6-bisphosphate (FBP) aldolase

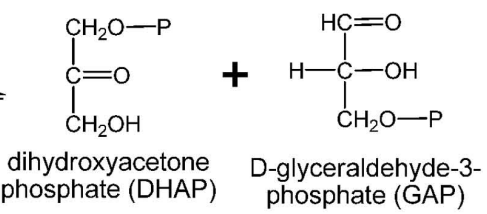

fructose 1,6-bis-

phosphate (FBP)

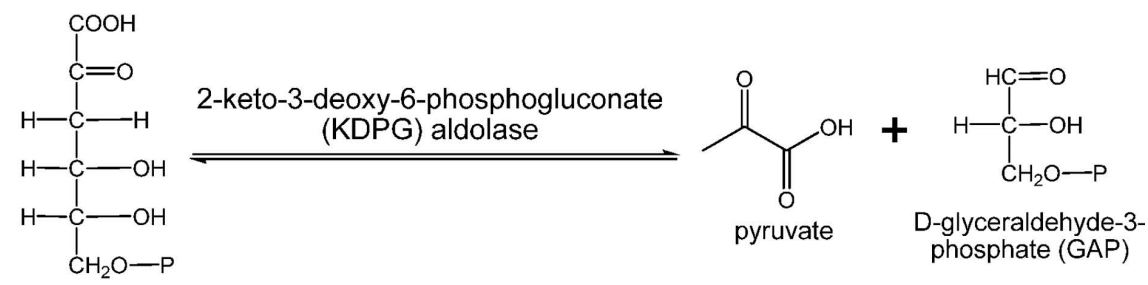

2-keto-3-deoxy-6-

phosphogluconat

(KDPG)

FIGURE 5 | Carbohydrate catabolism. The "classical" EMP, ED, and PP

pathways, which have been found in phototrophic bacteria, are shown in (A), and aldol condensation reactions catalyzed by FBP aldolase in the
$\mathrm{EMP} /$ gluconeogenic pathway and KDPG aldolase in the ED pathway are shown in (B). Abbreviation: EMP, Emden-Meyerhof-Parnas; ED, Entner-Doudoroff; KDPG, 2-keto-3-dehydro-6-phosphogluconate.
Anaerobic anoxygenic phototrophic Proteobacteria and aerobic anoxygenic phototrophic Proteobacteria. Anaerobic anoxygenic phototrophic Proteobacteria are the most metabolically versatile among photosynthetic bacteria. Some AnAPs are known to employ either the EMP or ED pathway, depending on growth conditions and nutrients, for carbohydrate catabolism, whereas the 
OPP pathway has not been reported to be active in AnAPs. Employing activity assays, sugar consumption, analysis of labeled amino acids using ${ }^{14} \mathrm{C}$-labeled sugar in wild-type and Glc-6phosphate dehydrogenase-deficient mutant, previous studies indicate that Rba. capsulatus and Rba. sphaeroides utilize the EMP (or the ED) pathway to oxidize fructose during phototrophic (or chemotrophic) growth, and operate the ED pathway to dissimilate glucose during both phototrophic and chemotrophic (dark) growth (Conrad and Schlegel, 1977, 1978; Fuhrer et al., 2005). Consistent with the experimental data, all of the genes in the ED pathway have been identified in the genome of Rba. capsulatus and Rba. sphaeroides. Other AnAPs are missing either the gene encoding 6-phosphogluconate dehydratase (such as Bradyrhizobium sp. BTAi1) or all of the genes (i.e., Rsp. centenum, Rsp. Rubrum, and all of the strains of Rps. palustris) in the ED pathway.

Genes in the ED pathway are present in the genomes of AAPs (Tang et al., 2009a), and an active ED pathway has been suggested in several AAPs (Yurkov and Beatty, 1998). Moreover, recent ${ }^{13} \mathrm{C}$-based metabolomics/fluxomics studies, transcriptomics, and activity assays indicate that two members of the AAPs, $R$. denitrificans OCh114 and Dinoroseobacter shibae DFL12, exclusively or mainly use the ED pathway to oxidize glucose. Both AAPs have an inactive EMP pathway (Furch et al., 2009; Tang et al., 2009a), even though all of the genes in the EMP pathway have been identified in the D. shibae genome (Furch et al., 2009). Like AnAPs, an active OPP pathway has also not been reported in AAPs (Yurkov and Beatty, 1998).

All of the marine Roseobacter species that have been sequenced have genes in the ED pathway in their genome (Moran et al., 2007; Brinkhoff et al., 2008). Many marine Roseobacter species are non-phototrophs, some of which have been shown to operate an active ED pathway (Yurkov and Beatty, 1998; Furch et al., 2009). Thus, both phototrophic and non-phototrophic Roseobacters utilize the ED pathway. Note that many strains of AAPs and AnAPs that use the ED pathway do not have the $p g d$ gene (encoding 6-phosphogluconate dehydrogenase) in the OPP pathway (Lim et al., 2009; Strnad et al., 2010) and/or the $p f k$ gene (encoding 6phosphofructokinase) in the EMP pathway (Swingley et al., 2007; Tang et al., 2009a). The selective evolutionary advantages of losing the $p f k$ gene and/or the $p g d$ gene, and having an inactive EMP pathway or/and the OPP pathway (Furch et al., 2009; Tang et al., 2009a), remain unclear.

Heliobacteria. D-Fructose and D-glucose can support phototrophic growth of Heliobacterium gestii, one of the heliobacteria discovered in tropical paddy soil (Madigan, 2006). Hbt. modestical$d u m$ is closely related to Hbt. gestii in phylogeny (Bryantseva et al., 1999). All of the genes in the EMP pathway are present in the Hbt. modesticaldum genome. Consistent with genomic annotation and phylogenetic analyses, recent studies demonstrate that D-glucose, D-fructose, and D-ribose can support the phototrophic growth of Hbt. modesticaldum with a trace amount of yeast extract supplied (Tang et al., 2010b). Because Hbt. modesticaldum has a complete EMP pathway, but does not have key genes in the OPP and ED pathways (Sattley et al., 2008), it is likely that Hbt. modesticaldum employs the EMP pathway for carbohydrate catabolism and hydrogen production as suggested in certain thermophilic microbes (de
Vrije et al., 2007). An active ED pathway has not been reported in any heliobacteria, consistent with the fact that very few Gram- $(+)$ bacteria employ the ED pathway.

Filamentous anoxygenic phototrophs. Most of the reports of carbohydrate metabolism of FAPs have focused on Cfl. aurantiacus, which is the most investigated FAP bacterium (or green non-sulfur/gliding bacterium). Cfl. aurantiacus has been reported to grow well on glucose and a number of other sugars during aerobic respiration (Madigan et al., 1974), and it uses the EMP pathway for carbohydrate catabolism (Krasilnikova et al., 1986). An active ED pathway has not been identified in FAPs. Gene annotation in Cfl. aurantiacus indicates that the PP pathway is complete (Tang et al., 2011), consistent with the activities reported for Glc6-phosphate dehydrogenase $(\mathrm{G} 6 \mathrm{PDH})$ and 6-phosphogluconate dehydrogenase (6PGDH), two essential enzymes in the OPP pathway (Krasilnikova et al., 1986). Note that the $f b a A$ gene encoding FBP aldolase in the EMP/gluconeogenic pathway is missing in the genome of Chloroflexi species (e.g., Cfl. aurantiacus, Chloroflexus sp. Y-400-fl, and Cfl. aggregans; Tang et al., 2011). If Cfl. aurantiacus were unable to synthesize FBP aldolase, an active OPP pathway would be employed for the interconversion of D-Glc-6-phosphate and GAP, so sugars can be converted to pyruvate and other energy-rich species, and vice versa. However, higher activities of phosphofructokinase and fructose 1,6-bisphosphate (FBP) aldolase have been found in Cfl. aurantiacus grown with glucose than with acetate (Krasilnikova and Kondrateva, 1987; Kondratieva et al., 1992; Hanada and Pierson, 2006). Thus, Cfl. aurantiacus and other Chloroflexi species may employ a novel FBP aldolase. Note that Roseiflexi species (Roseiflexus sp. RS-1 and Roseiflexus castenholzii), which are closely related to Chloroflexi species, have a putative a bifunctional FBP aldolase/phosphatase gene identified (Say and Fuchs, 2010). Genes encoding various types of aldolase are present in the Cfl. aurantiacus genome (Tang et al., 2011). Further work is needed to clarify this picture.

Cyanobacteria. Cyanobacteria can use the OPP pathway and the EMP pathway for carbohydrate dissimilation (Smith, 1982). Some cyanobacteria, such as Synechocystis sp. PCC 6803, can assimilate glucose during mixotrophic growth (Astier et al., 1984), and other species can grow on fructose (Wolk, 1973). Further, genes in the EMP pathway and the PP pathway have been identified in the genome of cyanobacteria. Fermentative growth of cyanobacteria with carbohydrates has been reported (Stal and Moezelaar, 1997), and the OPP pathway has been recognized to be the main route for oxidizing glucose (Carr, 1973; Smith, 1982) and providing the reducing equivalents to nitrogenase in diazotrophic cyanobacteria (Summers et al., 1995; Bergman et al., 1997). The importance of G6PDH and 6PGDH in the OPP pathway for the growth of cyanobacteria has been demonstrated (Scanlan et al., 1995; Hagen and Meeks, 2001; Knowles and Plaxton, 2003), and the reaction of G6PDH in cyanobacteria is also known to be regulated by thioredoxin (Cossar et al., 1984; Lindahl and Florencio, 2003). In addition, the EMP pathway in cyanobacteria is also suggested to be active. Other than glucose, some cyanobacteria, such as Cyanothece, can grow on glycerol (Feng et al., 
2010a). Glycerol is a precursor for biosynthesis of triacylglycerols, and can be also converted to GAP in the EMP/gluconeogenic pathway.

\section{Aldolases employed in the EMP and ED pathways.}

Figure $5 \mathbf{B}$ shows the reactions catalyzed by fructose 1,6bisphosphate (FBP) aldolase (EC 4.1.2.13) and 2-keto-3-deoxy-6phosphogluconate (KDPG) aldolase (EC 4.1.2.14). The reactions catalyzed by both aldolases are reversible. FBP aldolase, catalyzing the interconversion of FBP and D-glyceraldehyde-3-phosphate (GAP)/dihydroxyacetone phosphate (DHAP), is widely distributed in phototrophs due to being employed by both the EMP pathway and gluconeogenesis.

\section{FBP aldolase}

Different classes of FBP aldolases have been identified in archaea, bacteria, and eukaryotes (Say and Fuchs, 2010), and some FBP aldolases are also responsible for additional biological functions (Grochowski and White, 2008). All of the phototrophic bacteria, except FAPs, have the class II FBP aldolase (encoded by the $f b a A$ gene), which has been mainly found in bacteria and fungi. The $f b a B$ gene encoding the class I FBP aldolase, mainly found in eukaryotes, can also be identified in the genomes of AnAPs, AAPs, cyanobacteria, and heliobacteria. Further, a bifunctional FBP aldolase/phosphatase enzyme, which has no sequence homology with the classical FBP aldolases, was recently identified in some archaea. The bifunctional enzyme has been suggested to be an ancestral enzyme in gluconeogenesis (Say and Fuchs, 2010). Genes encoding the bifunctional FBP aldolase/phosphatase have also been found in the genomes of phototrophs Roseiflexi species (Say and Fuchs, 2010).

\section{KDPG aldolase}

KDPG aldolase, which catalyzes the interconversion of KDPG and GAP/pyruvate (Figure 5B), is one of the two enzymes specific for the ED pathway, and the other specific enzyme is 6phosphogluconate dehydratase. While KDPG aldolase is required in the ED pathway, KDPG aldolase is not specific to the ED pathway and is also responsible for Arg, Pro, glyoxylate, and dicarboxylase metabolism (Conway, 1992). KDPG aldolase has been identified in AnAPs (Conrad and Schlegel, 1977, 1978; Conway, 1992) and AAPs (Yurkov et al., 1991; Furch et al., 2009; Tang et al., 2009a) that use the ED pathway for carbohydrate oxidation. The ED pathway has not been reported in cyanobacteria, while the eda gene encoding KDPG aldolase has been found in the genome of many cyanobacterial strains. Although no detailed studies of KDPG aldolases from phototrophs have been reported, sequence alignments suggest that all of the phototrophic bacterial KDPG aldolases are the class I KDPG aldolases, which form an internal active site lysine-substrate aldimine for catalysis (Fullerton et al., 2006).

The structure-function relationships and reaction mechanism of the class I KDPG aldolase in non-phototrophs have been investigated intensively (Allard et al., 2001; Ahmed et al., 2005; Fullerton et al., 2006). These studies indicate that the class I KDPG aldolase in the phosphorylative, semi-phosphorylative and non-phosphorylative ED pathways has promiscuous substrate specificities, and can interact with phosphorylated and non-phosphorylated substrates, i.e., KDPG, 2-keto-3-deoxy-gluconate (KDG), GAP, and D-glyceraldehyde, pyruvate and its analogs, and a wide range of aldehyde components (Griffiths et al., 2002; Ahmed et al., 2005). Further, the enzyme from the aerobic thermophilic archaeon Sulfolobus solfataricus, and perhaps Thermoplasma acidophilum, and other thermoacidophilic Archaea, also has high relative activity with 2keto-3-deoxygalactonate (KDGal; Lamble et al., 2003). Directed evolution and site-directed mutagenesis have also been employed to further broaden the substrate specificities of the class I KDPG aldolase (Franke et al., 2004; Cheriyan et al., 2007).

\section{The tricarboxylic acid cycle}

Forward, reverse, and branched TCA cycles. Many metabolites in the TCA cycle are the precursors of amino acids and biomass. At least three forms of the TCA cycle have been identified in phototrophic bacteria: the forward TCA cycle (or the OTCA cycle), the reverse TCA cycle (or the RTCA cycle), and the branched (or incomplete) TCA cycle. The OTCA cycle or the Krebs cycle, discovered by Sir Hans Krebs more than seven decades ago (Krebs and Johnson, 1937), produces reducing equivalents and ATP, and is one of the most important, if not the most essential, central carbon and energy metabolic pathway in phototrophs and nonphototrophs. AnAPs (Imhoff et al., 2005; Madigan and Jung, 2009) and AAPs (Yurkov and Beatty, 1998; Furch et al., 2009; Tang et al., 2009a) employ an active OTCA cycle, like most non-phototrophic organisms. Cfl. aurantiacus operates the OTCA cycle under either aerobic (in darkness) or anaerobic (in the light) growth conditions (Sirevag and Castenholtz, 1979), whereas the family Oscillochloridaceae in FAPs have a partial RTCA cycle (Berg et al., 2005). GSBs channel the reducing equivalents generated via photosynthetic electron transport to the RTCA cycle, which functions as an autotrophic $\mathrm{CO}_{2}$ assimilation pathway for producing cellular material (Evans et al., 1966a; Sirevag, 1995). GSBs also operate the incomplete OTCA cycle (from citrate to $\alpha$-ketoglutarate) during mixotrophic growth with acetate (Feng et al., 2010b; Tang and Blankenship, 2010). Cyanobacteria have a branched TCA cycle and do not have enzymes catalyzing interconversion of $\alpha$ ketoglutarate and succinate (Stanier and Cohen-Bazire, 1977). The carbon flux via the branched TCA cycle is very low during photoautotrophic growth of cyanobacteria. In this case, cyanobacteria use the branched TCA cycle for synthesizing biomass rather than producing ATP and reducing equivalents (Shastri and Morgan, 2005).

Compared to the energy-producing OTCA cycle, metabolic flux in the RTCA cycle is energetically unfavorable. While several reactions in the TCA cycle are reversible, the reductive carboxylation of succinyl-CoA to $\alpha$-ketoglutarate (catalyzed by $\alpha$-ketoglutarate synthase) and of acetyl-CoA to pyruvate (catalyzed by pyruvate synthase) in the RTCA cycle are not thermodynamically favorable. The standard Gibbs free energy change of the decarboxylation of pyruvate in pyruvate synthase is estimated to be $-4.6 \mathrm{kcal} / \mathrm{mol}$ (Thauer et al., 1977). Thus, GSBs and other organisms using the RTCA cycle recruit strong reductants, such as reduced ferredoxin, to operate the carboxylation reactions catalyzed by pyruvate synthase and $\alpha$-ketoglutarate synthase and to proceed the RTCA cycle efficiently. 
Compared to other phototrophic bacteria, the carbon flow of heliobacteria has not been understood until recently. The enzyme activity of ATP citrate lyase, the key enzyme in the RTCA cycle, and (Si)-citrate synthase, the common enzyme for synthesizing citrate to initiate the OTCA cycle (see below), have not been detected in heliobacteria (Pickett et al., 1994; Tang et al., 2010a). Genes encoding ATP citrate lyase and ( $\mathrm{Si}$ )-citrate synthase have not been found in heliobacteria, whereas all other genes in the RTCA cycle have been found in Hbt. modesticaldum genome (Sattley et al., 2008). Feeding the cultures with $\left[2-{ }^{13} \mathrm{C}\right]$ acetate and probing the ${ }^{13} \mathrm{C}$-labeling patterns of Glu, Kelly, and coworkers suggested that Heliobacterium strain HY-3 uses the OTCA cycle to synthesize $\alpha$ ketoglutarate (Pickett et al., 1994). However, the authors cannot explain these observations with the lack of the (Si)-citrate synthase. Our recent studies indicate that Hbt. modesticaldum uses $(R e)$-citrate synthase to initiate the incomplete OTCA cycle (from citrate to $\alpha$-ketoglutarate) to synthesize Glu, and that carbon flux is mostly carried out through the incomplete OTCA cycle (Tang et al., 2010b).

\section{Enzymes operating in citrate metabolism} Enzymes that synthesize citrate

Citrate synthase is required for producing citrate through assimilating acetyl-CoA and OAA to initiate the OTCA cycle that generates reducing equivalents. The citrate synthase reported in current textbooks and most of the literature is $(\mathrm{Si})$-citrate synthase [(Si)CS; EC 2.3.3.1]. The majority of organisms, including four types of photosynthetic microbes: AAPs, AnAPs, FAPs, and cyanobacteria, use $(\mathrm{Si})$-CS to synthesize citrate from acetyl-CoA and OAA for initiating the OTCA cycle. The gltA gene encoding ( $\mathrm{Si}$ )-CS has also been identified in the genome of GSBs (Eisen et al., 2002; Davenport et al., 2010). Alternatively, the activity of (Si)-CS has not been detected in heliobacteria (Pickett et al., 1994; Tang et al., 2010b), and the gltA gene is absent in the Hbt. modesticaldum genome (Sattley et al., 2008). However, when performing the enzyme assays under anaerobic conditions, product turnover has been detected in cell-free extracts of $\mathrm{Hbt}$. modesticaldum with the addition of acetylCoA, OAA, and $\mathrm{Mn}^{2+}$ metal ions (Tang et al., 2010a). Further, the fifth carbon position of Glu has been found to be ${ }^{13} \mathrm{C}$-labeled using $\left[1-{ }^{13} \mathrm{C}\right]$ pyruvate, also suggesting that Hbt. modesticaldum synthesizes citrate via $(R e)$-citrate synthase $[(R e)$-CS; EC 2.3.3.3; Tang et al., 2010a]. If citrate is synthesized via ( $\mathrm{Si}$-CS, the first carbon position of Glu is expected to be labeled using $\left[1-{ }^{13} \mathrm{C}\right]$ pyruvate. Differences in the labeling patterns of Glu result from whether ( $\mathrm{Si}$ )-CS or $(\mathrm{Re})$-CS attaches the acetyl group at the pro-S or pro$R$ arm of OAA, respectively. The final product of $(R e)$-CS versus (Si)-CS is the same, since citrate is a symmetric molecule, while the intermediate, $(3 R)$-citryl-CoA versus $(3 S)$-citryl-CoA, is different (Figure 6A).

Compared to $(\mathrm{Si})$-CS, $(\mathrm{Re})$-CS is an unconventional enzyme for citrate biosynthesis, and is phylogenetically related to homocitrate synthase (EC 2.3.3.14) and 2-isopropylmalate synthase (Li et al., 2007). Homocitrate synthase catalyzes the formation of (3R)-homocitrate via the Claisen condensation of acetyl-CoA and $\alpha$-ketoglutarate (Tucci and Ceci, 1972; Wulandari et al., 2002; Figure 6A). Similar sequences and active site structures between 2 -isopropylmalate synthase and homocitrate synthase have also been suggested (Qian et al., 2008). Also, bacteria with the activity of $(R e)-C S$ reported often employ citramalate synthase for isoleucine synthesis (Feng et al., 2009; Tang et al., 2009b, 2010a). Together, $(R e)-C S$, homocitrate synthase (Figure 6A), 2isopropylmalate synthase, and citramalate synthase (Figure A1 in Appendix) catalyze Claisen condensation type reactions with similar $\alpha$-ketoacid substrates, and may have evolved from the same ancestor (Figure 7).

Sequence comparisons between $(\mathrm{Re})$-CS and $(\mathrm{Si})$-CS also suggest that these two types of CS are phylogenetically distinct ( $\mathrm{Li}$ et al., 2007). As indicated by other enzyme pairs that catalyze the formation of stereroisomers (Lamzin et al., 1995), dissimilar active site structures between $(\mathrm{Re})$-CS and $(\mathrm{Si})$-CS are expected to generate different citrate isomers. Moreover, unlike the potent inhibition of aconitase by (-)-erythro-2-F-citrate, previous studies have suggested that $(+)$-erythro-2-F-citrate, synthesized from 2fluoroacetate, and OAA by $(R e)-C S$, is not an inhibitor of aconitase (Lauble et al., 1996; Tang et al., 2010a).

While Hbt. modesticaldum does not have the gene encoding $(R e)-C S$, two genes encoding putative homocitrate synthases have been identified in the Hbt. modesticaldum genome (Sattley et al., 2008). Homocitrate has only one known task in cells: serving as the precursor for lysine biosynthesis via the $\alpha$-aminoadipate pathway. However, except for genes encoding putative homocitrate synthase, other genes in the $\alpha$-aminoadipate pathway (Figure A2 in Appendix) have not been identified in the Hbt. modesticaldum genome, so the function of the putative homocitrate synthases remains to be verified. Whether one of the putative homocitrate synthases or another gene product functions as $(R e)-C S$ in heliobacteria should be investigated.

\section{Enzymes that dissimilate citrate}

Cleavage of citrate through the RTCA cycle produces acetylCoA and OAA for building cellular material. Citrate cleavage in biological organisms can be accomplished by three enzymes: citrate lyase (EC 4.1.3.6), ATP citrate lyase (ACL; EC 4.1.3.8), or citryl-CoA synthetase (CCS; or so called citryl-CoA ligase) followed by citry-CoA lyase (CCL; Aoshima et al., 2004b; Hugler et al., 2007). The reaction of citrate lyase, which cleaves citrate into acetate and oxaloacetate (OAA), is distinct from ACL and CCS/CCL, which catalyze ATP-dependent cleavage of citrate to OAA and acetyl-CoA (Figure 6B). The phototrophic GSBs and some anaerobic bacteria use ACL to dissimilate citrate produced via the RTCA cycle into acetyl-CoA and OAA (Evans et al., 1966a; Wahlund and Tabita, 1997; Kanao et al., 2001; Kim and Tabita, 2006; Hugler et al., 2007; Voordeckers et al., 2008). The reaction catalyzed by the Cba. tepidum ACL in vivo has been suggested to be reversible (Tang and Blankenship, 2010), and ACL is also responsible for the citrate synthesis for acetate oxidation in the OTCA cycle in some anaerobic chemotrophic bacteria (Thauer et al., 1989). Moreover, ACL is also responsible for producing cytoplasmic acetyl-CoA for many biological processes in eukaryotic cells, such as histone acetylation, lipid production, a signal for activating glucose catabolism and apoptosis (Rathmell and Newgard, 2009; Wellen et al., 2009; Chu et al., 2010; Morrish et al., 2010; Wang et al., 2010; Zhao et al., 2010). 


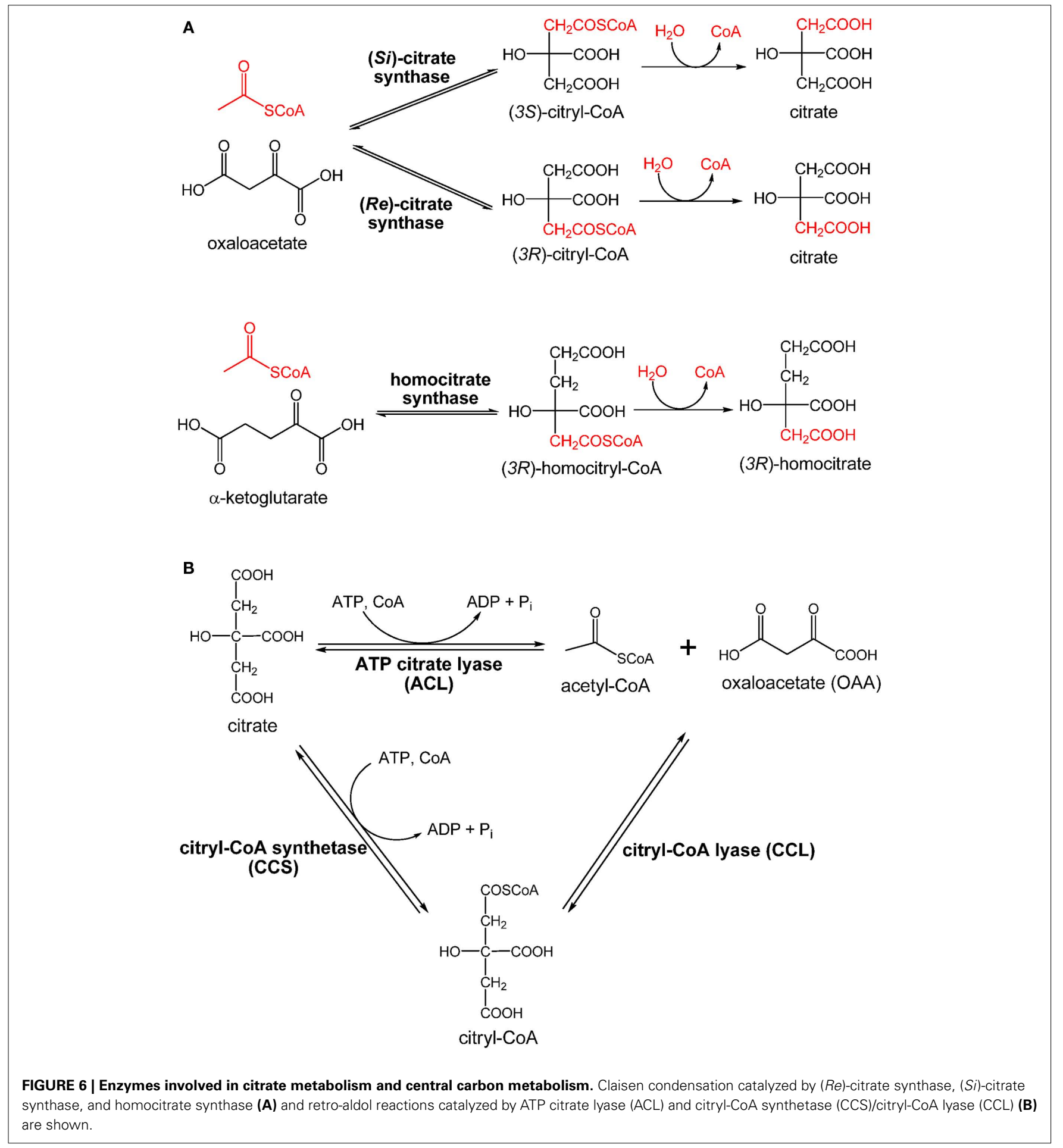

Different isoforms of ACLs have been identified. While a metazoan ACL (mACL) consists of a single polypeptide (Sun et al., 2010), ACL from other organisms, including other eukaryotic cells (fungi, yeast, and plants) and microorganisms, including GSBs (Wahlund and Tabita, 1997; Kim and Tabita, 2006), has two subunits (encoded by aclA and $a c l B$ ). Sequence comparisons between the one-subunit ACL (mACL) and the two-subunit ACL (non-mACL) suggest the one-subunit ACL is a gene fusion product of the two-subunit ACL. Also, a second type of ACL (the type II ACL) has also been reported recently in the magnetotactic $\alpha$-Proteobacterium Magnetococcus sp. MC-1, which uses the RTCA cycle for autotrophic $\mathrm{CO}_{2}$ fixation (Williams et al., 2006), and has also been proposed in several proteobacterial genomes (Hugler and Sievert, 2011). 


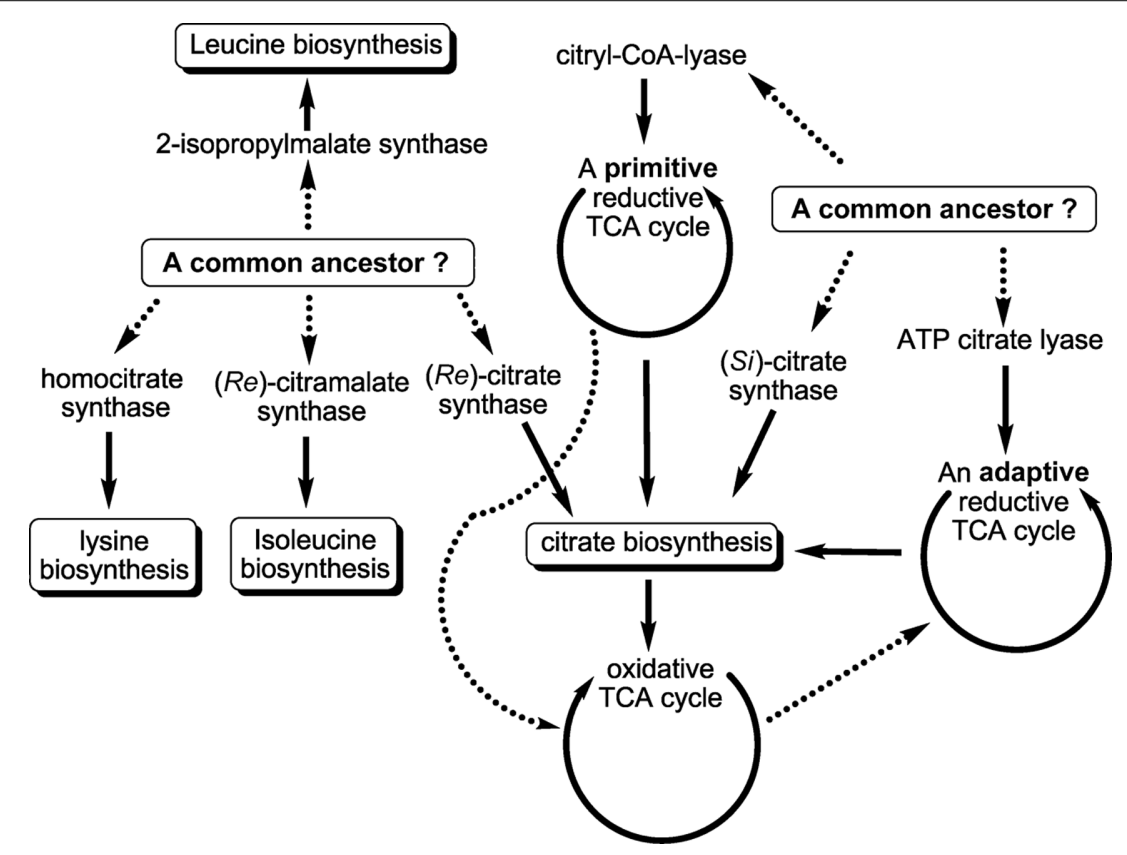

FIGURE 7 | Proposed evolutionary perspectives of some central carbon metabolic pathways. Previous studies suggested that 2-isopropylmalate synthase, homocitrate synthase, citramalate synthase, and $(R e)$-citrate synthase may have evolved from a common ancestor, and that (Si)-citrate synthase, ATP citrate lyase and citryl-CoA lyase may have evolved from another common ancestor. The oxidative TCA cycle was thought to have evolved from the primitive reductive TCA cycle, whereas the reductive TCA cycle operated in the GSBs has been proposed to be an adaptive form that may have evolved from the OTCA cycle. The proposed evolutionary links are shown in dashed lines.
The function of the type II ACL has not been biochemically confirmed.

While eukaryotes and most prokaryotes operate ACL, certain non-photosynthetic bacteria use CCL and CCS, instead of ACL, for citrate cleavage (Figure 6B). An obligately chemolithoautotrophic bacterium $H$. thermophilus (Aoshima et al., 2004a,b) and some members of the family Aquificaceae (Hugler et al., 2007) have been reported recently to use CCS and CCL to cleave citrate. Further, the iron-oxidizing bacterium Leptospirillum ferriphilum has genes encoding CCL and CCS, but not ACL, identified in the genome (Levican et al., 2008).

Citrate metabolism and the TCA cycle: evolution or adaptation? Citrate metabolism operates in every living cell. Citrate biosynthesis is required for initiating the OTCA cycle, and oxidation of citrate through the OTCA cycle creates reducing equivalents and energy. ATP-dependent citrate cleavage produces acetyl-CoA and OAA to build cellular material. (Re)-CS and (Si)-CS catalyze citrate biosynthesis and start the OTCA cycle, and ACL and CCS/CCL operate ATP-dependent citrate cleavage via the RTCA cycle. Sequence alignments suggest that $(\mathrm{Si})$-CS and CCL are phylogenetically relevant, and that ACL is likely a gene fusion product of (Si)-CS (or CCL) and succinyl-CoA synthetase. Sequences of CCS and succinyl-CoA synthetase are also similar (Aoshima et al., 2004a). Additionally, slight CCL activity has been reported in (Si)CS (Srere, 1963) and low (Si)-CS activity has also been found in the H. thermophilus CCL (Aoshima et al., 2004b). Based on the sequence homology of enzymes involved in citrate metabolism, (Si)-CS may have evolved from CCL and ACL may have evolved from CCL [or ( $\mathrm{Si}$ )-CS), CCS and succinyl-CoA synthetase (Aoshima et al., 2004b]. Note that some species in the Aquificae phylum use CCL/CCS and others operate ACL for citrate cleavage (Hugler et al., 2007), suggesting that ACL and CCL/CCS may share some evolutionary history. ACL, (Si)-CS, and CCL may have evolved from a common ancestor (Figure 7).

The OTCA cycle has been suggested to have evolved from the RTCA cycle (Wachtershauser, 1990). GSBs, which use ACL for citrate cleavage, may operate the RTCA cycle through an adaptation and horizontal gene transfer in response to environmental changes. Note that genes encoding ( $\mathrm{Si})-\mathrm{CS}(\mathrm{glt} A)$ and ACL ( aclBA) are present in the genomes of GSBs (Eisen et al., 2002; Davenport et al., 2010). The sequence information suggests that ACL may have evolved from (Si)-CS and succinyl-CoA synthetase (Aoshima et al., 2004b). In addition to the RTCA cycle, GSBs also operate a partial OTCA cycle during mixotrophic growth (Tang and Blankenship, 2010). Phylogenetic analyses with 16S rRNA genes of photosynthetic bacteria (Woese, 1987; Pace, 1997) suggest that GSBs evolved later than FAPs, which have an active OTCA cycle. Taken together, the RTCA cycle in GSBs may have evolved from the OTCA cycle. The proposed evolutionary lineages of citrate metabolism and the TCA cycle in the central carbon metabolic network are illustrated in Figure 7.

\section{EVOLUTIONARY PERSPECTIVES OF CENTRAL CARBON METABOLISM}

Understanding the evolution of photosynthesis is an important objective in a deeper understanding of the origin and development of photosynthetic diversity. Lateral and horizontal transfers of photosynthetic genes among phototrophic bacteria have been 
proposed during the evolution of photosynthesis (Nagashima et al., 1997; Raymond et al., 2002; Raymond and Blankenship, 2004), although it has not been generally accepted which bacteria were donors and which bacteria were recipients during gene transfers. The photosystems of photosynthetic bacteria have been well studied. Proteobacteria (AnAPs and AAPs) and FAPs have a type II (quinone type) RC, and GSBs, chloroacidobacteria and heliobacteria have a type I (Fe-S type) RC (Blankenship, 2002). Phototrophic bacteria containing the same type (or different types) of RCs have been known to use distinct (or similar) light-harvesting antenna complexes. For example, chlorosomes are present in Chloroflexi species (FAPs), GSBs, and chloroacidobacteria but absent in Proteobacteria, the Roseiflexi species (FAPs), and heliobacteria. Also, GSB, chloroacidobacteria and heliobacteria have a type I RC, while heliobacteria have no light-harvesting complexes other than antenna pigments that are part of the RC core complex. This is distinct from GSB and chloroacidobacteria, both of which contain chlorosomes and the Fenna-MatthewsOlson (FMO) complex. So there seems to be little correlation between the RC types and the light-harvesting antenna complexes in anoxygenic phototrophic bacteria. These features suggest horizontal gene transfers of RC or light-harvesting complexes among phototrophic bacteria. Moreover, some features in the carbon metabolism of phototrophic bacteria suggested below also suggest horizontal gene transfers between phototrophic and non-phototrophic bacteria.

\section{Central carbon metabolism of heliobacteria versus non-phototrophic Firmicutes}

Among GSBs, chloroacidobacteria, and heliobacteria, only GSBs are known to be photoautotrophs. Heliobacteria, the only Gram-(+) phototrophic bacteria, use $(R e)$-CS to produce citrate possibly via the $(3 R)$-citryl-CoA intermediate, and GSBs contain the gene encoding ( $\mathrm{Si}$ )-CS and use ACL and/or ( $\mathrm{Si}$ )$\mathrm{CS}$ to synthesize $(\mathrm{Si})$-CS. Previous studies indicate that several Clostridia species exclusively use $(R e)$-CS to synthesize citrate (Li et al., 2007). Additionally, two types of phosphoglycerate mutase (PGM) have been reported to catalyze the interconversion of 2-phosphoglycerate and 3-phosphoglycerate in carbohydrate metabolism: the cofactor-dependent PGM (dPGM) and cofactorindependent PGM (iPGM). It has been suggested that APGM may be evolutionarily related to a family of acid phosphatases and to fructose 2,6-bisphosphatase (Schneider et al., 1993), and that iPGM has been derived from the family of alkaline phosphatase and sulfatases (Galperin et al., 1998). Heliobacteria have the gpmI gene (encoding iPGM; Sattley et al., 2008) and GSBs have the gpmA gene (encoding dPGM). Likewise, members of the Gram$(+)$ bacteria, including spore-forming Firmicutes (Bacillus and

\section{REFERENCES}

Ahmed, H., Ettema, T. J., Tjaden, B., Geerling, A. C., van der Oost, J., and Siebers, B. (2005). The semi-phosphorylative EntnerDoudoroff pathway in hyperthermophilic archaea: a re-evaluation. Biochem. J. 390, 529-540.
Alber, B. E., Spanheimer, R., EbenauJehle, C., and Fuchs, G. (2006). Study of an alternate glyoxylate cycle for acetate assimilation by Rhodobacter sphaeroides. Mol. Microbiol. 61, 297-309.

Albers, H., and Gottschalk, G. (1976). Acetate metabolism in

Clostridium), use iPGM, whereas most of the Gram-(-) bacteria employ dPGM. Moreover, although both GSBs and heliobacteria have pyruvate synthase $/ \alpha$-ketoglutarate synthase instead of pyruvate dehydrogenase/ $\alpha$-ketoglutarate dehydrogenase, their carbon flow patterns in the TCA cycle are entirely different (Feng et al., 2010b; Tang and Blankenship, 2010; Tang et al., 2010a). Together, gene/enzyme pairs in citrate biosynthesis and sugar metabolism, and carbon flow in the TCA cycle of heliobacteria versus GSBs clearly indicate that their carbon metabolism correlates with the $16 \mathrm{~S}$ rRNA-based phylogeny of the group (Firmicutes), rather than with the presence of the photosynthetic RC. According to many similarities in carbon metabolism between heliobacteria and non-phototrophic Firmicutes, either genes encoding carbon metabolism in non-phototrophic Firmicutes may have been transferred from or to heliobacteria, or genes encoding photosystems in heliobacteria may have been transferred from other photosynthetic bacteria. The latter hypothesis is consistent with the fact that heliobacteria have the simplest photosystem among phototrophic bacteria (Madigan, 2006; Heinnickel and Golbeck, 2007; Sattley et al., 2008; Sattley and Blankenship, 2010).

\section{CONCLUSION}

All life on Earth requires carbon sources and energy. Phototrophic bacteria use light as the energy source for autotrophic, mixotrophic and also heterotrophic growth. The carbon metabolism in photosynthetic bacteria is not only essential for constructing cellular material, but also providing reducing equivalents for photosynthetic electron transport during photoheterotrophic growth. The central carbon metabolism of photosynthetic bacteria has received more attention recently, mainly due to their metabolic versatility and/or uniqueness as well as the information acquired from systematic analyses. This review illustrates that photosynthetic bacteria employ many unconventional central carbon metabolic pathways and novel enzymes in response to their ecological niches, whereas certain carbon assimilation pathways remain to be understood. Further, both evolutionary origin and late adaptation have been suggested for several of the central metabolic enzymes and pathways. Together, the rich knowledge accumulated for central carbon metabolism, along with the information obtained from the genes of $16 \mathrm{~S}$ rRNA, various enzymes and photosynthetic components, is expected to shed more light on the origin and evolution of photosynthesis.

\section{ACKNOWLEDGMENTS}

This work was supported by the Exobiology Program of NASA Grant NNX08AP62G (Robert Eugene Blankenship) and National Science Foundation Career Grant MCB0954016 (Yinjie J. Tang).

Rhodopseudomonas gelatinosa and several other Rhodospirillaceae. Arch. Microbiol. 111, 45-49.

Allard, J., Grochulski, P., and Sygusch, J. (2001). Covalent intermediate trapped in 2-keto-3-deoxy-6- phosphogluconate (KDPG) aldolase structure at $1.95-\mathrm{A}$ resolution.
Proc. Natl. Acad. Sci. U.S.A. 98, 3679-3684

Aoshima, M., Ishii, M., and Igarashi, Y (2004a). A novel enzyme, citryl-CoA synthetase, catalysing the first step of the citrate cleavage reaction in Hydrogenobacter thermophilus TK-6. Mol. Microbiol. 52, 751-761. 
Aoshima, M., Ishii, M., and Igarashi, Y. (2004b). A novel enzyme, citrylCoA lyase, catalysing the second step of the citrate cleavage reaction in Hydrogenobacter thermophilus TK-6. Mol. Microbiol. 52, 763-770.

Astier, C., Elmorjani, K., Meyer, I., Joset, F., and Herdman, M. (1984). Photosynthetic mutants of the cyanobacteria Synechocystis sp. strains PCC 6714 and PCC 6803: sodium phydroxymercuribenzoate as a selective agent. J. Bacteriol. 158, 659-664.

Bandyopadhyay, A., Stockel, J., Min, H., Sherman, L. A., and Pakrasi, H. B. (2010). High rates of photobiological $\mathrm{H} 2$ production by a cyanobacterium under aerobic conditions. Nat. Commun. 1, 139.

Bassham, J. A., Benson, A. A., and Calvin, M. (1950). The path of carbon in photosynthesis. J. Biol. Chem. 185, 781-787.

Berg, I. A., Keppen, O. I., Krasil'nikova, E. N., Ugol'kova, N. V., and Ivanovskii, R. N. (2005). Carbon metabolism of filamentous anoxygenic phototrophic bacteria of the family Oscillochloridaceae. Microbiology 74, 258-264.

Berg, I. A., Kockelkorn, D., Buckel, W., and Fuchs, G. (2007). A 3-hydroxypropionate/4hydroxybutyrate autotrophic carbon dioxide assimilation pathway in archaea. Science 318, 1782-1786.

Berg, I. A., Kockelkorn, D., RamosVera, W. H., Say, R. F., Zarzycki, J., Hugler, M., Alber, B. E., and Fuchs, G. (2010). Autotrophic carbon fixation in archaea. Nat. Rev. Microbiol. 8, 447-460.

Bergman, B., Gallon, J. R., Rai, A. N., and Sta, L. J. (1997). N2 fixation by nonheterocystous cyanobacteria. FEMS Microbiol. Rev. 19, 139-185.

Biebl, H., Allgaier, M., Tindall, B. J., Koblizek, M., Lunsdorf, H., Pukall, R., and Wagner-Dobler, I. (2005). Dinoroseobacter shibae gen. nov., sp. nov., a new aerobic phototrophic bacterium isolated from dinoflagellates. Int. J. Syst. Evol. Microbiol. 55, 1089-1096.

Biebl, H., Tindall, B. J., Pukall, R., Lunsdorf, H., Allgaier, M., and WagnerDobler, I. (2006). Hoeflea phototrophica sp. nov., a novel marine aerobic alphaproteobacterium that forms bacteriochlorophyll a. Int. J. Syst. Evol. Microbiol. 56, 821-826.

Blankenship, R. E. (2002). Molecular Mechanisms of Photosynthesis. Oxford: Blackwell Science Ltd.

Bricker, T. M., Zhang, S., Laborde, S. M., Mayer, P. R. III, Frankel, L. K., and Moroney, J. V. (2004). The malic enzyme is required for optimal photoautotrophic growth of Synechocystis sp. strain PCC 6803 under continuous light but not under a diurnal light regimen. J. Bacteriol. 186, 8144-8148.

Brinkhoff, T., Giebel, H. A., and Simon, M. (2008). Diversity, ecology, and genomics of the Roseobacter clade: a short overview. Arch. Microbiol. 189, 531-539.

Bryant, D. A., Costas, A. M., Maresca, J. A., Chew, A. G., Klatt, C. G., Bateson, M. M., Tallon, L. J., Hostetler, J., Nelson, W. C., Heidelberg, J. F., and Ward, D. M. (2007). Candidatus Chloracidobacterium thermophilum: an aerobic phototrophic Acidobacterium. Science 317 , 523-526.

Bryant, D. A., and Frigaard, N. U. (2006). Prokaryotic photosynthesis and phototrophy illuminated. Trends Microbiol. 14, 488-496.

Bryantseva, I. A., Gorlenko, V. M., Kompantseva, E. I., Achenbach, L. A., and Madigan, M. T. (1999). Heliorestis daurensis, gen. nov. sp.nov., an alkaliphilic rod-to-coiled-shaped phototrophic heliobacterium from a siberian soda lake. Arch Microbiol $172,167-174$

Buchanan, B. B., and Arnon, D. I. (1990). A reverse KREBS cycle in photosynthesis: consensus at last. Photosyn. Res. 24, 47-53.

Calvin, M. (1989). 40 years of photosynthesis and related activities. Photosyn. Res. 21, 3-16.

Calvin, M., and Benson, A. A. (1948). The path of carbon in photosynthesis. Science 107, 476-480.

Carr, N. G. (1973). Mechanism of autotrophic physiology in blue green algae. J. Gen. Microbiol. 75, R5-R6.

Chen, Y. B., Dominic, B., Mellon, M. T., and Zehr, J. P. (1998). Circadian rhythm of nitrogenase gene expression in the diazotrophic filamentous nonheterocystous cyanobacterium Trichodesmium sp. strain IMS 101. J. Bacteriol. 180 3598-3605.

Cheriyan, M., Toone, E. J., and Fierke, C. A. (2007). Mutagenesis of the phosphate-binding pocket of KDPG aldolase enhances selectivity for hydrophobic substrates. Protein Sci. 16, 2368-2377.

Chu, K. Y., Lin, Y., Hendel, A. Kulpa, J. E., Brownsey, R. W., and Johnson, J. D. (2010). ATP-citrate lyase reduction mediates palmitateinduced apoptosis in pancreatic beta cells. J. Biol. Chem. 285, 32606-32615.
Conrad, R., and Schlegel, H. G. (1977). Different degradation pathways for glucose and fructose in Rhodopseudomonas capsulata. Arch. Microbiol. 112, 39-48.

Conrad, R., and Schlegel, H. G. (1978). An alternative pathway for the degradation of endogenous fructose during the catabolism of sucrose in Rhodopseudomonas capsulata. J. Gen. Microbiol. 105, 305-313.

Conway, T. (1992). The EntnerDoudoroff pathway: history, physiology and molecular biology. FEMS Microbiol. Rev. 9, 1-27.

Cossar, J. D., Rowell, P., and Stewart, W. D. P. (1984). Thioredoxin as a modulator of glucose-6-phosphate dehydrogenase in a N2-fixing cyanobacterium. J. Gen. Microbiol. 130 991-998.

Davenport, C., Ussery, D. W., and Tummler, B. (2010). Comparative genomics of green sulfur bacteria. Photosyn. Res. 104, 137-152.

de Vrije, T., Mars, A. E., Budde, M. A., Lai, M. H., Dijkema, C., de Waard, P., and Claassen, P. A. (2007) Glycolytic pathway and hydrogen yield studies of the extreme thermophile Caldicellulosiruptor saccharolyticus. Appl. Microbiol. Biotechnol. 74, 1358-1367.

Dobrinski, K. P., Longo, D. L., and Scott, K. M. (2005). The carbonconcentrating mechanism of the hydrothermal vent chemolithoautotroph Thiomicrospira crunogena. J. Bacteriol. 187, 5761-5766.

Doolittle, W. F. (1998). You are what you eat: a gene transfer ratchet could account for bacterial genes in eukaryotic nuclear genomes. Trend Genet. 14, 307-311.

Eisen, J. A., Nelson, K. E., Paulsen, I. T., Heidelberg, J. F., Wu, M., Dodson, R. J., Deboy, R., Gwinn, M. L., Nelson, W. C., Haft, D. H., Hickey, E. K., Peterson, J. D., Durkin, A S., Kolonay, J. L., Yang, F., Holt, I., Umayam, L. A., Mason, T., Brenner, M., Shea, T. P., Parksey, D., Nierman, W. C., Feldblyum, T. V., Hansen, C. L., Craven, M. B., Radune, D. Vamathevan, J., Khouri, H., White, O., Gruber, T. M., Ketchum, K. A. Venter, J. C., Tettelin, H., Bryant D. A., and Fraser, C. M. (2002) The complete genome sequence of Chlorobium tepidum TLS, a photosynthetic, anaerobic, green-sulfur bacterium. Proc. Natl. Acad. Sci. U.S.A. 99, 9509-9514.

Ensign, S. A. (2006). Revisiting the glyoxylate cycle: alternate pathways for microbial acetate assimilation. Mol. Microbiol. 61, 274-276.
Erb, T. J., Berg, I. A., Brecht, V., Muller, M., Fuchs, G., and Alber B. E. (2007). Synthesis of C5dicarboxylic acids from $\mathrm{C} 2$-units involving crotonyl-CoA carboxylase/reductase: the ethylmalonylCoA pathway. Proc. Natl. Acad. Sci. U.S.A. 104, 10631-10636.

Erb, T. J., Fuchs, G., and Alber, B. E. (2009). (2S)-MethylsuccinylCoA dehydrogenase closes the ethylmalonyl-CoA pathway for acetyl-CoA assimilation. Mol. Microbiol. 73, 992-1008.

Evans, M. C., Buchanan, B. B., and Arnon, D. I. (1966a). New cyclic process for carbon assimilation by a photosynthetic bacterium. Science 152,673 .

Evans, M. C., Buchanan, B. B. and Arnon, D. I. (1966b). A new ferredoxin-dependent carbon reduction cycle in a photosynthetic bacterium. Proc. Natl. Acad. Sci. U.S.A. 55, 928-934.

Falcone, D. L., and Tabita, F. R. (1991). Expression of endogenous and foreign ribulose 1,5-bisphosphate carboxylase-oxygenase (RubisCO) genes in a RubisCO deletion mutan of Rhodobacter sphaeroides. J. Bacteriol. 173, 2099-2108.

Feng, X., Bandyopadhyay, A., Berla, B. Page, L., Wu, B., Pakrasi, H. B., and Tang, Y. J. (2010a). Mixotrophic and photoheterotrophic metabolism in Cyanothece sp. ATCC 51142 under continuous light. Microbiology 156, 2566-2574

Feng, X., Tang, K. H., Blankenship, R. E., and Tang, Y. J. (2010b). Metabolic flux analysis of the mixotrophic metabolisms in the green sulfur bacterium Chlorobaculum tepidum. J. Biol. Chem. 285, 39544-39550.

Feng, X., Mouttaki, H., Lin, L., Huang, R., Wu, B., Hemme, C. L., He, Z., Zhang, B., Hicks, L. M., Xu, J., Zhou, J., and Tang, Y. J. (2009). Characterization of the central metabolic pathways in Thermoanaerobacter sp. X514 via isotopomer-assisted metabolite analysis. Appl. Environ. Microbiol. 75, 5001-5008.

Franke, D., Hsu, C. C., and Wong, C. H. (2004). Directed evolution of aldolases. Meth. Enzymol. 388, 224-238.

Fuchs, B. M., Spring, S., Teeling, H., Quast, C., Wulf, J., Schattenhofer, M., Yan, S., Ferriera, S., Johnson, J., Glockner, F. O., and Amann, R. (2007). Characterization of a marine gammaproteobacterium capable of aerobic anoxygenic photosynthesis. Proc. Natl. Acad. Sci. U.S.A. 104, 2891-2896. 
Fuhrer, T., Fischer, E., and Sauer, U. (2005). Experimental identification and quantification of glucose metabolism in seven bacterial species. $J$. Bacteriol. 187, 1581-1590.

Fullerton, S. W., Griffiths, J. S., Merkel, A. B., Cheriyan, M., Wymer, N. J., Hutchins, M. J., Fierke, C. A., Toone, E. J., and Naismith, J. H. (2006). Mechanism of the class I KDPG aldolase. Bioorg. Med. Chem. 14, 3002-3010.

Furch, T., Preusse, M., Tomasch, J., Zech, H., Wagner-Dobler, I., Rabus, R., and Wittmann, C. (2009). Metabolic fluxes in the central carbon metabolism of Dinoroseobacter shibae and Phaeobacter gallaeciensis, two members of the marine Roseobacter clade. BMC Microbiol. 9 , 209. doi: 10.1186/1471-2180-9-209

Galperin, M. Y., Bairoch, A., and Koonin, E. V. (1998). A superfamily of metalloenzymes unifies phosphopentomutase and cofactorindependent phosphoglycerate mutase with alkaline phosphatases and sulfatases. Protein Sci. 7, 1829-1835.

Griffiths, J. S., Wymer, N. J., Njolito, E., Niranjanakumari, S., Fierke, C. A., and Toone, E. J. (2002). Cloning, isolation and characterization of the Thermotoga maritima KDPG aldolase. Bioorg. Med. Chem. 10, 545-550.

Grochowski, L. L., and White, R. H. (2008). Promiscuous anaerobes: new and unconventional metabolism in methanogenic archaea. Ann. N. Y. Acad. Sci. 1125, 190-214.

Hagen, K. D., and Meeks, J. C. (2001). The unique cyanobacterial protein OpcA is an allosteric effector of glucose-6-phosphate dehydrogenase in Nostoc punctiforme ATCC 29133. J. Biol. Chem. 276, 11477-11486.

Hallenbeck, P. L., Lerchen, R., Hessler, P., and Kaplan, S. (1990a). Roles of CfxA, CfxB, and external electron acceptors in regulation of ribulose 1,5-bisphosphate carboxylase/oxygenase expression in Rhodobacter sphaeroides. J. Bacteriol. 172, 1736-1748.

Hallenbeck, P. L., Lerchen, R., Hessler, P., and Kaplan, S. (1990b). Phosphoribulokinase activity and regulation of $\mathrm{CO} 2$ fixation critical for photosynthetic growth of Rhodobacter sphaeroides. J. Bacteriol. 172, 1749-1761.

Hanada, S., and Pierson, B. K. (2006). The Family Chloroflexaceae. The Prokaryotes, 3rd Edn, Vol. 7. New York: Springer, 815-842.

Hanada, S., Takaichi, S., Matsuura, K., and Nakamura, K. (2002). Roseiflexus castenholzii gen. nov., sp. nov., a thermophilic, filamentous, photosynthetic bacterium that lacks chlorosomes. Int. J. Syst. Evol. Microbiol. 52, 187-193.

Heinnickel, M., and Golbeck, J. H. (2007). Heliobacterial photosynthesis. Photosyn. Res. 92, 35-53.

Herter, S., Fuchs, G., Bacher, A., and Eisenreich, W. (2002). A bicyclic autotrophic $\mathrm{CO} 2$ fixation pathway in Chloroflexus aurantiacus. J. Biol. Chem. 277, 20277-20283.

Hohmann-Marriott, M. F., and Blankenship, R. E. (2011). Evolution of photosynthesis. Annu. Rev. Plant Biol. 62, 515-548.

Holo, H. (1989). Chloroflexus aurantiacus secretes 3-hydroxypropionate, a possible intermediate in the assimilation of $\mathrm{CO} 2$ and acetate. Arch. Microbiol. 151, 252-256.

Holthuijzen, Y. A., Van Breemen, J. F. L., Konings, W. N., and Van Bruggen, E. F. J. (1986). Electron microscopic studies of carboxysomes of Thiobacillus neopolitanus. Arch. Microbiol. 144, 258-262.

Huber, H., Gallenberger, M., Jahn, U., Eylert, E., Berg, I. A., Kockelkorn, D., Eisenreich, W., and Fuchs, G. (2008). A dicarboxylate/4hydroxybutyrate autotrophic carbon assimilation cycle in the hyperthermophilic Archaeum Ignicoccus hospitalis. Proc. Natl. Acad. Sci. U.S.A. 105, 7851-7856.

Hugler, M., Huber, H., Molyneaux, S. J., Vetriani, C., and Sievert, S. M. (2007). Autotrophic CO2 fixation via the reductive tricarboxylic acid cycle in different lineages within the phylum Aquificae: evidence for two ways of citrate cleavage. Environ. Microbiol. 9, 81-92.

Hugler, M., Petersen, J. M., Dubilier, N., Imhoff, J. F., and Sievert, S. M. (2011). Pathways of carbon and energy metabolism of the epibiotic community associated with the deep-sea hydrothermal vent shrimp Rimicaris exoculata. PLoS ONE 6, e16018. doi: 10.1371/journal.pone. 0016018

Hugler, M., and Sievert, S. M. (2011). Beyond the Calvin cycle: autotrophic carbon fixation in the ocean. Ann. Rev. Mar. Sci. 3, 261-289.

Hugler, M., Wirsen, C. O., Fuchs, G., Taylor, C. D., and Sievert, S. M. (2005). Evidence for autotrophic $\mathrm{CO} 2$ fixation via the reductive tricarboxylic acid cycle by members of the epsilon subdivision of proteobacteria. J. Bacteriol. 187, 3020-3027.

Imhoff, J. F., Hiraishi, A., and Suling, J. (2005). "Anoxygenic phototrophic purple bacteria," in Bergeys
Manual of Systematic Bacteriology, eds D. J. Brenner, N. R. Krieg, and J. T. Staley (New York: Springer), 119-132.

Ivanovsky, R. N., Krasilnikova, E. N., and Berg, I. A. (1997). A proposed citramalate cycle for acetate assimilation in the purple nonsulfur bacterium Rhodospirillum rubrum. FEMS Microbiol. Lett. 153, 399-404.

Iwai, M., Takizawa, K., Tokutsu, R., Okamuro, A., Takahashi, Y., and Minagawa, J. (2010). Isolation of the elusive supercomplex that drives cyclic electron flow in photosynthesis. Nature 464, 1210-1213.

Joshi, H. M., and Tabita, F. R. (1996). A global two component signal transduction system that integrates the control of photosynthesis, carbon dioxide assimilation, and nitrogen fixation. Proc. Natl. Acad. Sci. U.S.A. 93, 14515-14520.

Kanao, T., Fukui, T., Atomi, H., and Imanaka, T. (2001). ATP-citrate lyase from the green sulfur bacterium Chlorobium limicola is a heteromeric enzyme composed of two distinct gene products. Eur. J. Biochem. 268, 1670-1678.

Kaplan, A., and Reinhold, L. (1999). $\mathrm{CO} 2$ concentrating mechanisms in photosynthetic microorganisms. Annu. Rev. Plant Physiol. Plant Mol. Biol. 50, 539-570.

Kawasumi, T., Igarashi, Y., Kodama, T., and Minoda, Y. (1984). Hydrogenobacter thermophilus gen. nov, sp. nov,. an extremely thermophilic, aerobic, hydrogen oxidizing bacterium. Int. J. Syst. Bacteriol. 34, 5-10.

Kim, W., and Tabita, F. R. (2006). Both subunits of ATP-citrate lyase from Chlorobium tepidum contribute to catalytic activity. J. Bacteriol. 188, 6544-6552.

Klatt, C. G., Bryant, D. A., and Ward, D. M. (2007). Comparative genomics provides evidence for the 3-hydroxypropionate autotrophic pathway in filamentous anoxygenic phototrophic bacteria and in hot spring microbial mats. Environ. Microbiol. 9, 2067-2078.

Knowles, V. L., and Plaxton, W. C. (2003). From genome to enzyme: analysis of key glycolytic and oxidative pentose-phosphate pathway enzymes in the cyanobacterium Synechocystis sp. PCC 6803. Plant Cell Physiol. 44, 758-763.

Koblizek, M., Beja, O., Bidigare, R. R., Christensen, S., Benitez-Nelson, B., Vetriani, C., Kolber, M. K., Falkowski, P. G., and Kolber, Z. S. (2003). Isolation and characterization of Erythrobacter sp. strains from the upper ocean. Arch. Microbiol $180,327-338$.

Kolber, Z. S., Plumley, F. G., Lang, A. S., Beatty, J. T., Blankenship, R. E., VanDover, C. L., Vetriani, C., Koblizek, M., Rathgeber, C., and Falkowski, P. G. (2001). Contribution of aerobic photoheterotrophic bacteria to the carbon cycle in the ocean. Science 292, 2492-2495.

Kondratieva, E. N., Ivanovsky, R. N., and Krasilnikova, E. N. (1992). Carbon metabolism in Chloroflexus aurantiacus. FEMS Microbiol. Lett. 100, 269-271.

Kornberg, H. L., and Krebs, H. A. (1957). Synthesis of cell constituents from $\mathrm{C} 2$-units by a modified tricarboxylic acid cycle. Nature 179, 988-991.

Korotkova, N., Chistoserdova, L., Kuksa, V., and Lidstrom, M. E. (2002). Glyoxylate regeneration pathway in the methylotroph Methylobacterium extorquens AM1. J. Bacteriol. 184, 1750-1758.

Kramer, D. M., Schoepp, B., Liebl, U., and Nitschke, W. (1997). Cyclic electron transfer in Heliobacillus mobilis involving a menaquinol-oxidizing cytochrome bc complex and an RCItype reaction center. Biochemistry 36, 4203-4211.

Krasilnikova, E. N., Keppen, O. I., Gorlenko, V. M., and Kondrateva, E. N. (1986). Growth of Chloroflexus aurantiacus on media with different organic compounds and pathways of their metabolism. Microbiology 55, 325-329.

Krasilnikova, E. N., and Kondrateva, E. N. (1987). Growth of Chloroflexus aurantiacus under anaerobic conditions in the dark and the metabolism of organic substrates. Microbiology 56, 281-285.

Krebs, H. A., and Johnson, W. A. (1937). The role of citric acid in intermediate metabolism in animal tissues. Enzymologia 4, 148-156.

Kruger, N. J., and von Schaewen, A. (2003). The oxidative pentose phosphate pathway: structure and organisation. Curr. Opin. Plant Biol. 6, 236-246.

Kusian, B., and Bowien, B. (1997). Organization and regulation of $\mathrm{cbb} \mathrm{CO} 2$ assimilation genes in autotrophic bacteria. FEMS Microbiol. Rev. 21 135-155.

Laguna, R., Tabita, F. R., and Alber, B. E. (2011). Acetate-dependent photoheterotrophic growth and the differential requirement for the Calvin-Benson-Bassham reductive pentose phosphate cycle in Rhodobacter sphaeroides and Rhodopseudomonas palustris. Arch. Microbiol. 193, 151-154. 
Lamble, H. J., Heyer, N. I., Bull, S. D., Hough, D. W., and Danson, M. J. (2003). Metabolic pathway promiscuity in the archaeon Sulfolobus solfataricus revealed by studies on glucose dehydrogenase and 2-keto3-deoxygluconate aldolase. J. Biol. Chem. 278, 34066-34072.

Lamzin, V. S., Dauter, Z., and Wilson, K. S. (1995). How nature deals with stereoisomers. Curr. Opin. Struct. Biol. 5, 830-836.

Lauble, H., Kennedy, M. C., Emptage, M. H., Beinert, H., and Stout, C. D. (1996). The reaction of fluorocitrate with aconitase and the crystal structure of the enzyme-inhibitor complex. Proc. Natl. Acad. Sci. U.S.A. 93, 13699-13703.

Levican, G., Ugalde, J. A., Ehrenfeld, N., Maass, A., and Parada, P. (2008). Comparative genomic analysis of carbon and nitrogen assimilation mechanisms in three indigenous bioleaching bacteria: predictions and validations. BMC Genomics 9, 581. doi: 10.1186/1471-2164-9-581

Li, F., Hagemeier, C. H., Seedorf, H., Gottschalk, G., and Thauer, R. K. (2007). Re-citrate synthase from Clostridium kluyveri is phylogenetically related to homocitrate synthase and isopropylmalate synthase rather than to Si-citrate synthase. J. Bacteriol. 189, 4299-4304.

Li, Z., Yu, J., Kim, K. R., and Brand, J. (2010). Nitrogen fixation by a marine non-heterocystous cyanobacterium requires a heterotrophic bacterial consort. Environ. Microbiol. 12, 1185-1193.

Lim, S. K., Kim, S. J., Cha, S. H., Oh, Y. K., Rhee, H. J., Kim, M. S., and Lee, J. K. (2009). Complete genome sequence of Rhodobacter sphaeroides KD131. J. Bacteriol. 191, 1118-1119.

Lindahl, M., and Florencio, F. J. (2003). Thioredoxin-linked processes in cyanobacteria are as numerous as in chloroplasts, but targets are different. Proc. Natl. Acad. Sci. U.S.A. 100, 16107-16112.

Ljungdahl, L. G. (1986). The autotrophic pathway of acetate synthesis in acetogenic bacteria. Annu. Rev. Microbiol. 40, 415-450.

Lu, Y. K., Marden, J., Han, M., Swingley, W. D., Mastrian, S. D., Chowdhury, S. R., Hao, J., Helmy, T., Kim, S., Kurdoglu, A. A., Matthies, H. J., Rollo, D., Stothard, P., Blankenship, R. E., Bauer, C. E., and Touchman, J. W. (2010). Metabolic flexibility revealed in the genome of the cyst-forming alpha-1 proteobacterium Rhodospirillum centenum. BMC Genomics 11, 325. doi: 10.1186/1471-2164-11-325

Madigan, M. T. (2006). "The family Heliobacteriaceae," in The Prokaryotes, 3rd Edn, Vol. 4, eds
M. Dworkin, E. Rosenberg, K.-H. Schleifer, and E. Stackebrandt (New York: Springer), 951-964.

Madigan, M. T., and Jung, D. O. (2009). "An overview of purple bacteria: systematics, physiology, and habitats," in The Purple Phototrophic Bacteria, eds C. N. Hunter, F. Daldal, M. C. Thurnauer, and J. T. Beatty (Dordrecht: Springer Academic Publishers), 1-15.

Madigan, M. T., Petersen, S. R., and Brock, T. D. (1974). Nutritional studies on Chloroflexus, a filamentous photosynthetic, gliding bacterium. Arch. Microbiol. 100, 97-103.

Margulis, L. (1968). Evolutionary criteria in thallophytes: a radical alternative. Science 161, 1020-1022.

McKinlay, J. B., and Harwood, C. S. (2010). Carbon dioxide fixation as a central redox cofactor recycling mechanism in bacteria. Proc. Natl. Acad. Sci. U.S.A. 107, 11669-11675.

McKinlay, J. B., and Harwood, C. S. (2011). Calvin cycle flux, pathway constraints, and substrate oxidation state together determine the h2 biofuel yield in photoheterotrophic bacteria. MBio 2, e00323-e00310.

Moran, M. A., Belas, R., Schell, M. A., Gonzalez, J. M., Sun, F., Sun, S., Binder, B. J., Edmonds, J., Ye, W., Orcutt, B., Howard, E. C., Meile, C. Palefsky, W., Goesmann, A., Ren, Q., Paulsen, I., Ulrich, L. E., Thompson, L. S., Saunders, E., and Buchan, A. (2007). Ecological genomics of marine Roseobacter. Appl. Environ. Microbiol. 73, 4559-4569.

Morrish, F., Noonan, J., Perez-Olsen, C., Gafken, P. R., Fitzgibbon, M. Kelleher, J., VanGilst, M., and Hockenbery, D. (2010). Myc-dependent mitochondrial generation of acetylCoA contributes to fatty acid biosynthesis and histone acetylation during cell cycle entry. J. Biol. Chem. 285, 36267-36274.

Nagashima, K. V., Hiraishi, A., Shimada, K., and Matsuura, K. (1997). Horizontal transfer of genes coding for the photosynthetic reaction centers of purple bacteria. J. Mol. Evol. 45, 131-136.

Nelson, D. L., and Cox, M. M. (2008). Lehninger Principles of Biochemistry 5th Edn, New York, NY: W. H. Freeman.

Neuera, G., and Bothe, H. (1983). Anaplerotic reactions in Anabaena cylindrica. FEBS Lett. 158, 79-83.

Oda, Y., Larimer, F. W., Chain, P. S., Malfatti, S., Shin, M. V., Vergez, L. M., Hauser, L., Land, M. L., Braatsch, S., Beatty, J. T., Pelletier, D. A., Schaefer, A. L., and Harwood, C. S. (2008). Multiple genome sequences reveal adaptations of a phototrophic bacterium to sediment microenviron- ments. Proc. Natl. Acad. Sci. U.S.A. 105, 18543-18548.

Owttrim, G. W., and Colman, B. (1988). Phosphoenolpyruvate carboxylase mediated carbon flow in a cyanobacterium. Biochem. Cell Biol. 66, 93-99.

Pace, N. R. (1997). A molecular view of microbial diversity and the biosphere. Science 276, 734-740.

Pandelia, M. E., Nitschke, W., Infossi, P., Giudici-Orticoni, M. T., Bill, E. and Lubitz, W. (2011). Characterization of a unique [FeS] cluster in the electron transfer chain of the oxygen tolerant $[\mathrm{NiFe}]$ hydrogenase from Aquifex aeolicus. Proc. Natl. Acad. Sci. U.S.A. 108 6097-6102.

Peyraud, R., Kiefer, P., Christen, P., Massou, S., Portais, J. C., and Vorholt, J. A. (2009). Demonstration of the ethylmalonyl-CoA pathway by using 13C metabolomics. Proc. Natl. Acad. Sci. U.S.A. 106, 4846-4851.

Pickett, M. W., Williamson, M. P., and Kelly, D. J. (1994). An enzyme and 13C-NMR of carbon metabolism in heliobacteria. Photosyn. Res. 41, 75-88.

Qian, J., Khandogin, J., West, A. H., and Cook, P. F. (2008). Evidence for a catalytic dyad in the active site of homocitrate synthase from Saccharomyces cerevisiae. Biochemistry 47 6851-6858.

Rathmell, J. C., and Newgard, C. B. (2009). Biochemistry. A glucose-togene link. Science 324, 1021-1022.

Raven, J. (2009). Contributions of anoxygenic and oxygenic phototrophy and chemolithotrophy to carbon and oxygen fluxes in aquatic environments. Aquat. Microb. Ecol. $56,177-192$.

Raymond, J., and Blankenship, R. E. (2004). Biosynthetic pathways, gene replacement and the antiquity of life. Geobiology 2, 199-203.

Raymond, J., Zhaxybayeva, O., Gogarten, J. P., Gerdes, S. Y., and Blankenship, R. E. (2002). Whole-genome analysis of photosynthetic prokaryotes. Science 298, 1616-1620.

Sattley, W. M., and Blankenship, R. E. (2010). Insights into heliobacterial photosynthesis and physiology from the genome of Heliobacterium modesticaldum. Photosyn. Res. 104, 113-122.

Sattley, W. M., Madigan, M. T., Swingley, W. D., Cheung, P. C., Clocksin, K. M., Conrad, A. L., Dejesa, L. C., Honchak, B. M., Jung, D. O., Karbach, L. E., Kurdoglu, A., Lahiri, S. Mastrian, S. D., Page, L. E., Taylor, H. L., Wang, Z. T., Raymond, J., Chen, M., Blankenship, R. E., and Touchman, J. W. (2008). The genome of Heliobacterium modesticaldum, a phototrophic representative of the Firmicutes containing the simplest photosynthetic apparatus. J. Bacteriol. 190, 4687-4696.

Say, R. F., and Fuchs, G. (2010) Fructose 1,6-bisphosphate aldolase/phosphatase may be an ancestral gluconeogenic enzyme. Nature 464, 1077-1081.

Scanlan, D. J., Sundaram, S., Newman, J., Mann, N. H., and Carr, N. G. (1995). Characterization of a zwf mutant of Synechococcus sp. strain PCC 7942. J. Bacteriol. 177, 2550-2553.

Schneider, G., Lindqvist, Y., and Vihko, P. (1993). Three-dimensional structure of rat acid phosphatase. EMBO J. 12, 2609-2615.

Selig, M., Xavier, K. B., Santos, H., and Schonheit, P. (1997) Comparative analysis of EmbdenMeyerhof and Entner-Doudoroff glycolytic pathways in hyperthermophilic archaea and the bacterium Thermotoga. Arch. Microbiol. 167, 217-232.

Shastri, A. A., and Morgan, J. A. (2005). Flux balance analysis of photoautotrophic metabolism. Biotechnol. Prog. 21, 1617-1626.

Shiba, H., Kawasumi, T., Igarashi, Y., Kodama, T., and Minoda, Y. (1985). The CO2 assimilation via the reductive tricarboxylic acid cycle in an obligately autotrophic, aerobic hydrogen oxidizing bacterium, Hydrogenobacter thermophilus. Arch. Microbiol. 141, 198-203.

Shiba, T. (1991). Roseobacter litoralis gen. nov., sp. nov. and Roseobacter denitrificans sp. nov., aerobic pinkpigmented bacteria which contain bacteriochlorophyll a. Syst. Appl. Microbiol. 14, 140-145.

Shiba, T., and Harashima, K. (1986). Aerobic photosynthetic bacteria. Microbiol. Sci. 3, 376-378.

Shiba, T., and Simidu, U. (1982). Erythrobacter longus gen. nov., sp. nov. an aerobic bacterium which contains bacteriochlorophyll a. Int. J. Syst. Bacteriol. 32, 211-217.

Sirevag, R. (1995). "Carbon metabolism in green bacteria," in Anoxygenic Photosynthetic Bacteria, eds R. E. Blankenship, M. T. Madigan, and C. E. Bauer (Amsterdam: Kluwer), 871-883.

Sirevag, R., and Castenholtz, R. W. (1979). Aspects of carbon metabolism in Chloroflexus. Arch. Microbiol. 120, 151-153.

Smejkalova, H., Erb, T. J., and Fuchs, G. (2010). Methanol assimilation in Methylobacterium extorquens AM1: demonstration of all enzymes and their regulation. PLoS ONE 5, e13001. doi: 10.1371/journal.pone. 0013001 
Smith, A. J. (1982). "Modes of cyanobacterial carbon metabolism," in The Biology of Cyanobacteria, eds N. G. Carr and B. A. Whitton (Oxford: Blackwell Scientific Publications), 47-86.

Sorokin, D. Y., Trotsenko, Y. A., Doronina, N. V., Tourova, T. P., Galinski, E. A., Kolganova, T. V., and Muyzer, G. (2007). Methylohalomonas lacus gen. nov., sp. nov. and Methylonatrum kenyense gen. nov., sp. nov., methylotrophic gammaproteobacteria from hypersaline lakes. Int. J. Syst. Evol. Microbiol. 57, 2762-2769.

Srere, P. A. (1963). Citryl-CoA and the citrate condensing enzyme. Biochim. Biophys. Acta 77, 693-696.

Stal, L. J., and Moezelaar, R. (1997). Fermentation in cyanobacteria. FEMS Microbiol. Rev. 21, 179-211.

Stanier, R. Y., and Cohen-Bazire, G. (1977). "Photosynthetic prokaryotes: the cyanobacteria," in Annual Review of Microbiology, eds M. P. Starr, J. L. Ingraham, and A. Balows (Palo Alto, CA: Annual Reviews Inc.), 225-274.

Stockel, J., Jacobs, J. M., Elvitigala, T. R., Liberton, M., Welsh, E. A., Polpitiya, A. D., Gritsenko, M. A., Nicora, C. D., Koppenaal, D. W., Smith, R. D., and Pakrasi, H. B. (2011). Diurnal rhythms result in significant changes in the cellular protein complement in the cyanobacterium cyanothece 51142. PLoS ONE 6, e16680. doi: 10.1371/journal.pone.0016680

Strauss, G., and Fuchs, G. (1993). Enzymes of a novel autotrophic $\mathrm{CO} 2$ fixation pathway in the phototrophic bacterium Chloroflexus aurantiacus, the 3-hydroxypropionate cycle. Eur. J. Biochem. 215, 633-643.

Strnad, H., Lapidus, A., Paces, J., Ulbrich, P., Vlcek, C., Paces, V., and Haselkorn, R. (2010). Complete genome sequence of the photosynthetic purple nonsulfur bacterium Rhodobacter capsulatus SB 1003. J. Bacteriol. 192, 3545-3546.

Summers, M. L., Wallis, J. G., Campbell, E. L., and Meeks, J. C. (1995). Genetic evidence of a major role for glucose-6-phosphate dehydrogenase in nitrogen fixation and dark growth of the cyanobacterium Nostoc sp. strain ATCC 29133. J. Bacteriol. 177, 6184-6194.

Sun, T., Hayakawa, K., Bateman, K. S., and Fraser, M. E. (2010). Identification of the citrate-binding site of human ATP-citrate lyase using X-ray crystallography. J. Biol. Chem. 285, 27418-27428.

Swingley, W. D., Sadekar, S., Mastrian, S. D., Matthies, H. J., Hao, J., Ramos, H., Acharya, C. R., Conrad, A. L., Taylor, H. L., Dejesa, L. C., Shah,
M. K., O'Huallachain, M, E., Lince, M. T., Blankenship, R. E., Beatty, J. T., and Touchman, J. W. (2007). The complete genome sequence of Roseobacter denitrificans reveals a mixotrophic rather than photosynthetic metabolism. J. Bacteriol. 189, 683-690.

Tabita, F. R. (1995). "The biochemistry and metabolic regulation of carbon metabolism and $\mathrm{CO} 2$ fixation in purple bacteria," in Anoxygenic Photosynthetic Bacteria, eds R. E. Blankenship, M. T. Madigan, and C. E. Bauer (Amsterdam: Kluwer), 885-914.

Takai, K., Campbell, B. J., Cary, S. C., Suzuki, M., Oida, H., Nunoura, T., Hirayama, H., Nakagawa, S., Suzuki, Y., Inagaki, F., and Horikoshi, K. (2005). Enzymatic and genetic characterization of carbon and energy metabolisms by deep-sea hydrothermal chemolithoautotrophic isolates of Epsilonproteobacteria. Appl. Environ. Microbiol. 71, 7310-7320.

Tang, K. H., Barry, K., Chertkov, O., Dalin, E., Han, C. S., Hauser, L. J., Honchak, B. M., Karbach, L. E., Land, M. L., Lapidus, A., Larimer, F. W., Mikhailova, N., Pitluck, S., Pierson, B. K., and Blankenship, R. E. (2011). Complete genome sequence of the filamentous anoxygenic phototrophic bacterium Chloroflexus aurantiacus. BMC Genomics 12, 334. doi: 10.1186/1471-2164$12-334$

Tang, K. H., and Blankenship, R. E. (2010). Both forward and reverse TCA cycles operate in green sulfur bacteria. J. Biol. Chem. 285, 35848-35854.

Tang, K. H., Feng, X., Tang, Y. J., and Blankenship, R. E. (2009a). Carbohydrate metabolism and carbon fixation in Roseobacter denitrificans OCh114. PLoS ONE 4, e7233. doi: 10.1371/journal.pone.0007233

Tang, Y. J., Yi, S., Zhuang, W. Q., Zinder, S. H., Keasling, J. D., and Alvarez-Cohen, L. (2009b). Investigation of carbon metabolism in "Dehalococcoides ethenogenes" strain 195 by use of isotopomer and transcriptomic analyses. J. Bacteriol. 191, 5224-5231.

Tang, K. H., Feng, X., Zhuang, W. Q., Alvarez-Cohen, L., Blankenship, R. E., and Tang, Y. J. (2010a). Carbon flow of heliobacteria is related more to clostridia than to the green sulfur bacteria. J. Biol. Chem. 285, 35104-35112.

Tang, K. H., Yue, H., and Blankenship, R. E. (2010b). Energy metabolism of Heliobacterium modesticaldum during phototrophic and chemotrophic growth. BMC Microbiol. 10, 150. doi: 10.1186/1471-2180-10-150

Thauer, R. K. (2007). Microbiology. A fifth pathway of carbon fixation. Science 318, 1732-1733.

Thauer, R. K., Jungermann, K., and Decker, K. (1977). Energy conservation in chemotropic anaerobic bacteria. Bacteriol. Rev. 41, 100-180.

Thauer, R. K., Moller-Zinkhan, D., and Spormann, A. M. (1989). Biochemistry of acetate catabolism in anaerobic chemotrophic bacteria. Annu. Rev. Microbiol. 43, 43-67.

Tripp, H. J., Bench, S. R., Turk, K. A., Foster, R. A., Desany, B. A., Niazi, F., Affourtit, J. P., and Zehr J. P. (2010). Metabolic streamlining in an open-ocean nitrogen-fixing cyanobacterium. Nature 464, 90-94.

Tucci, A. F., and Ceci, L. N. (1972) Homocitrate synthase from yeast. Arch. Biochem. Biophys. 153 742-750.

Voordeckers, J. W., Do, M. H., Hugler, M., Ko, V., Sievert, S. M., and Vetriani, C. (2008). Culture dependent and independent analyses of 16S rRNA and ATP citrate lyase genes: a comparison of microbial communities from different black smoker chimneys on the MidAtlantic Ridge. Extremophiles 12, 627-640.

Wachtershauser, G. (1990). Evolution of the first metabolic cycles. Proc. Natl. Acad. Sci. U.S.A. 87, 200-204.

Wahlund, T. M., and Tabita, F. R. (1997). The reductive tricarboxylic acid cycle of carbon dioxide assimilation: initial studies and purification of ATP-citrate lyase from the green sulfur bacterium Chlorobium tepidum. J. Bacteriol. 179 4859-4867.

Wang, Q., Zhang, Y., Yang, C., Xiong, H., Lin, Y., Yao, J., Li, H., Xie, L., Zhao, W., Yao, Y., Ning, Z. B., Zeng, R. Xiong, Y., Guan, K. L., Zhao, S., and Zhao, G. P. (2010). Acetylation of metabolic enzymes coordinates carbon source utilization and metabolic flux. Science 327, 1004-1007.

Wang, X., Modak, H. V., and Tabita, F. R. (1993). Photolithoautotrophic growth and control of $\mathrm{CO} 2 \mathrm{fix}$ ation in Rhodobacter sphaeroides and Rhodospirillum rubrum in the absence of ribulose bisphosphate carboxylase-oxygenase. J. Bacteriol. 175, 7109-7114.

Wellen, K. E., Hatzivassiliou, G., Sachdeva, U. M., Bui, T. V. Cross, J. R., and Thompson, C. B. (2009). ATP-citrate lyase links cellular metabolism to histone acetylation. Science 324, 1076-1080.

Williams, T. J., Zhang, C. L., Scott, J. H., and Bazylinski, D. A. (2006). Evidence for autotrophy via the reverse tricarboxylic acid cycle in the marine magnetotactic coccus strain MC-1. Appl. Environ. Microbiol. 72, 1322-1329.

Woese, C. R. (1987). Bacterial evolution. Microbiol. Rev. 51, 221-271.

Wolk, C. P. (1973). Physiology and cytological chemistry of blue-green algae. Bacteriol. Rev. 37, 32-101.

Wood, H. G. (1991). Life with CO or $\mathrm{CO} 2$ and $\mathrm{H} 2$ as a source of carbon and energy. FASEB J. 5, 156-163.

Wulandari, A. P., Miyazaki, J., Kobashi, N., Nishiyama, M., Hoshino, T., and Yamane, H. (2002). Characterization of bacterial homocitrate synthase involved in lysine biosynthesis. FEBS Lett. 522, 35-40.

Yang, C., Hua, Q., and Shimizu, K. (2002). Quantitative analysis of intracellular metabolic fluxes using GC-MS and two-dimensional NMR spectroscopy. J. Biosci. Bioeng. 93, 78-87.

Yurkov, V., Jappe, J., and Vermeglio, A. (1996). Tellurite resistance and reduction by obligately aerobic photosynthetic bacteria. Appl. Environ Microbiol. 62, 4195-4198.

Yurkov, V. V., and Beatty, J. T. (1998). Aerobic anoxygenic phototrophic bacteria. Microbiol. Mol. Biol. Rev 62, 695-724.

Yurkov, V. V., and Csotonyi, J. T. (2009). "New light on aerobic anoxygenic phototrophs," in The Purple Phototrophic Bacteria, eds C. N. Hunter, F. Daldal, M. C. Thurnauer, and J. T. Beatty (Dordrecht: Springer Academic Publishers), 31-55.

Yurkov, V. V., Krasilnikova, E. N., and Gorlenko, V. M. (1991). Enzymes Involved in heterotrophic carbon metabolism of aerobic Erythrobacter sibiricus and Erythrobacter longus bacteria containing bacteriochlorophyll a. Microbiology 60 , 401-403.

Zarzycki, J., Brecht, V., Muller, M., and Fuchs, G. (2009). Identifying the missing steps of the autotrophic 3-hydroxypropionate $\mathrm{CO} 2$ fixation cycle in Chloroflexus aurantiacus. Proc. Natl. Acad. Sci. U.S.A. 106, 21317-21322.

Zehr,J. P., Bench, S. R., Carter, B. J.,Hewson, I., Niazi, F., Shi, T., Tripp, H J., and Affourtit, J. P. (2008). Globally distributed uncultivated oceanic N2-fixing cyanobacteria lack oxygenic photosystem II. Science 322, 1110-1112.

Zhang, S., Laborde, S. M., Frankel, L. K. and Bricker, T. M. (2004). Four novel genes required for optimal photoautotrophic growth of the cyanobacterium Synechocystis sp. strain PCC 6803 identified by in vitro transposon mutagenesis. J. Bacteriol. 186 875-879. 
Zhao, S., Xu, W., Jiang, W., Yu, W., Lin, Y., Zhang, T., Yao, J., Zhou, L., Zeng, Y., Li, H., Li, Y., Shi, J., An, W., Hancock, S. M., He, F., Qin, L., Chin, J., Yang, P., Chen, X., Lei, Q., Xiong, Y., and Guan, K. L. (2010). Regulation of cellular metabolism by protein lysine acetylation. Science 327, 1000-1004.
Conflict of Interest Statement: The authors declare that the research was conducted in the absence of any commercial or financial relationships that could be construed as a potential conflict of interest.

Received: 06 April 2011; accepted: 18 July 2011; published online: 01 August 2011.
Citation: Tang K-H, Tang YJ and Blankenship RE (2011) Carbon metabolic pathways in phototrophic bacteria and their broader evolutionary implications. Front. Microbio. 2:165. doi: 10.3389/fmicb.2011.00165

This article was submitted to Frontiers in Microbial Physiology and Metabolism, a specialty of Frontiers in Microbiology.
Copyright (C) 2011 Tang, Tang and Blankenship. This is an open-access article subject to a non-exclusive license between the authors and Frontiers Media $S A$, which permits use, distribution and reproduction in other forums, provided the original authors and source are credited and other Frontiers conditions are complied with. 


\section{APPENDIX \\ APPROACHES FOR INVESTIGATING CARBON METABOLISM OF PHOTOTROPHS}

Prior to the availability of genomic information, the carbon metabolism of phototrophic organisms was investigated by activity assays, together with stable isotope-labeling (Strauss et al., 1992; Pickett et al., 1994) or radioactive isotopic-labeling experiments (Bassham et al., 1950; Evans et al., 1966b; Conrad and Schlegel, 1977). Recently, functional characterization of phototrophic organisms has been accelerated because: (1) The instruments and data analyses of GC-/LC-MS (gas/liquid chromatography-mass spectrometry) and NMR (nuclear magnetic resonance) have been significantly improved; (2) high-throughput sequencing methods have determined complete genomes of photosynthetic organisms and many of their genomes have been fully annotated; and (3) more systematic approaches (i.e., "omics"), such as transcriptomics, proteomics, metabolomics, and fluxomics (Sauer, 2006; Peyraud et al., 2009; Singh et al., 2009; Stitt et al., 2010; Tripp et al., 2010), have been developed. Among these metabolomics approaches, ${ }^{13} \mathrm{C}$-based metabolic analysis and ${ }^{13} \mathrm{C}$-flux analysis have been recognized as powerful tools to probe active carbon metabolic pathways in vivo via feeding cells with a ${ }^{13} \mathrm{C}$-labeled carbon source and tracing ${ }^{13} \mathrm{C}$-labeling patterns in biomass and metabolites. Table A1 in Appendix illustrates several carbon metabolic pathways in phototrophic bacteria probed by ${ }^{13} \mathrm{C}$-labeled protein-based amino acids (Pickett et al., 1994; Furch et al., 2009; Peyraud et al., 2009; Tang et al., 2009a, 2010a; Feng et al., 2010a,b; Wu et al., 2010). In cooperation with in vivo physiological studies (or so called "physiomics"; Sanford et al., 2002), activity assays, and in vitro biochemical characterizations (Alber et al., 2006; Berg et al., 2007; Zarzycki et al., 2009), more knowledge and new insights into carbon metabolism of photosynthetic and non-photosynthetic microbes have been revealed.

\section{CITRAMALATE SYNTHASE AND 2-ISOPROPYLMALATE SYNTHASE}

Citramalate synthase (EC 2.3.1.182), catalyzing the formation of $(2 R)$-citramalate via the Claisen condensation of acetyl-CoA and pyruvate, is the first and the only specific enzyme employed in the citramalate pathway, which directly converts pyruvate to 2ketobutyrate for isoleucine biosynthesis (Figure A2 in Appendix). All of the other enzymes in the citramalate pathway are also engaged in leucine biosynthesis (Xu et al., 2004). While citramalate synthase can only be identified in organisms that operate the citramalate pathway (Howell et al., 1999), 2-isopropylmalate synthase (EC 2.3.3.13), catalyzing the formation of (2S)-2-isopropylmalate via the Claisen condensation of 2-oxoisovalerate and acetyl-CoA, is universally required for leucine biosynthesis. 2-oxoisovalerate is also the precursor of valine. High sequence homology $(\sim 50 \%$ identity and $\sim 70 \%$ similarity) between citramalate synthase and 2-isopropylmalate synthase has been reported (Howell et al., 1999; Xu et al., 2004; Risso et al., 2008), in agreement with similar substrates for these two enzymes (Figure A1 in Appendix).

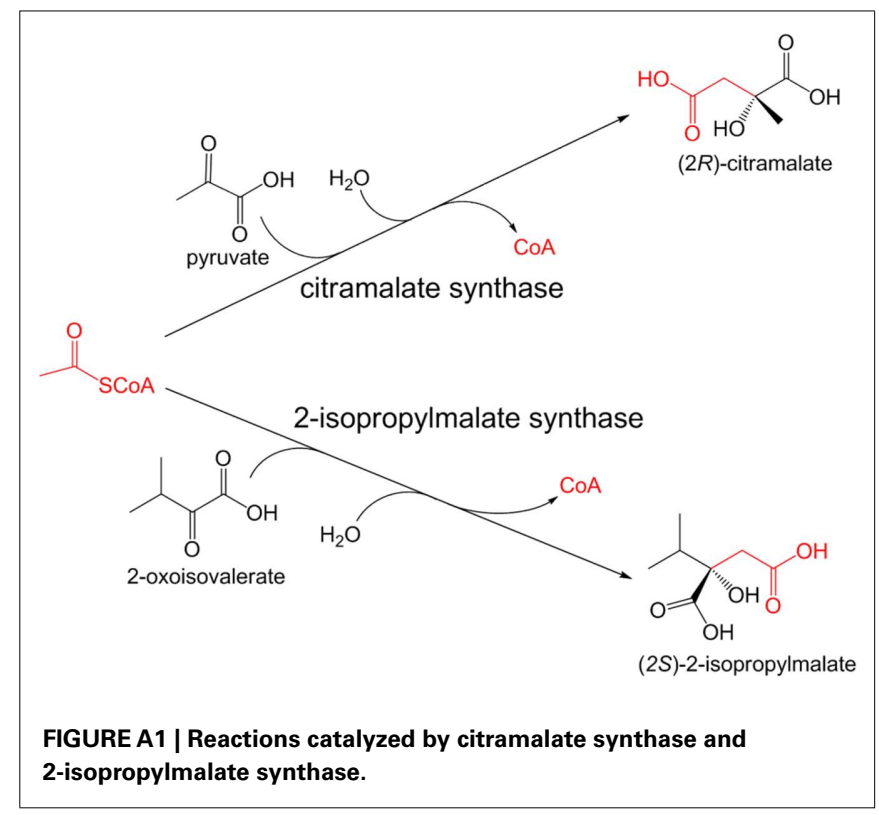




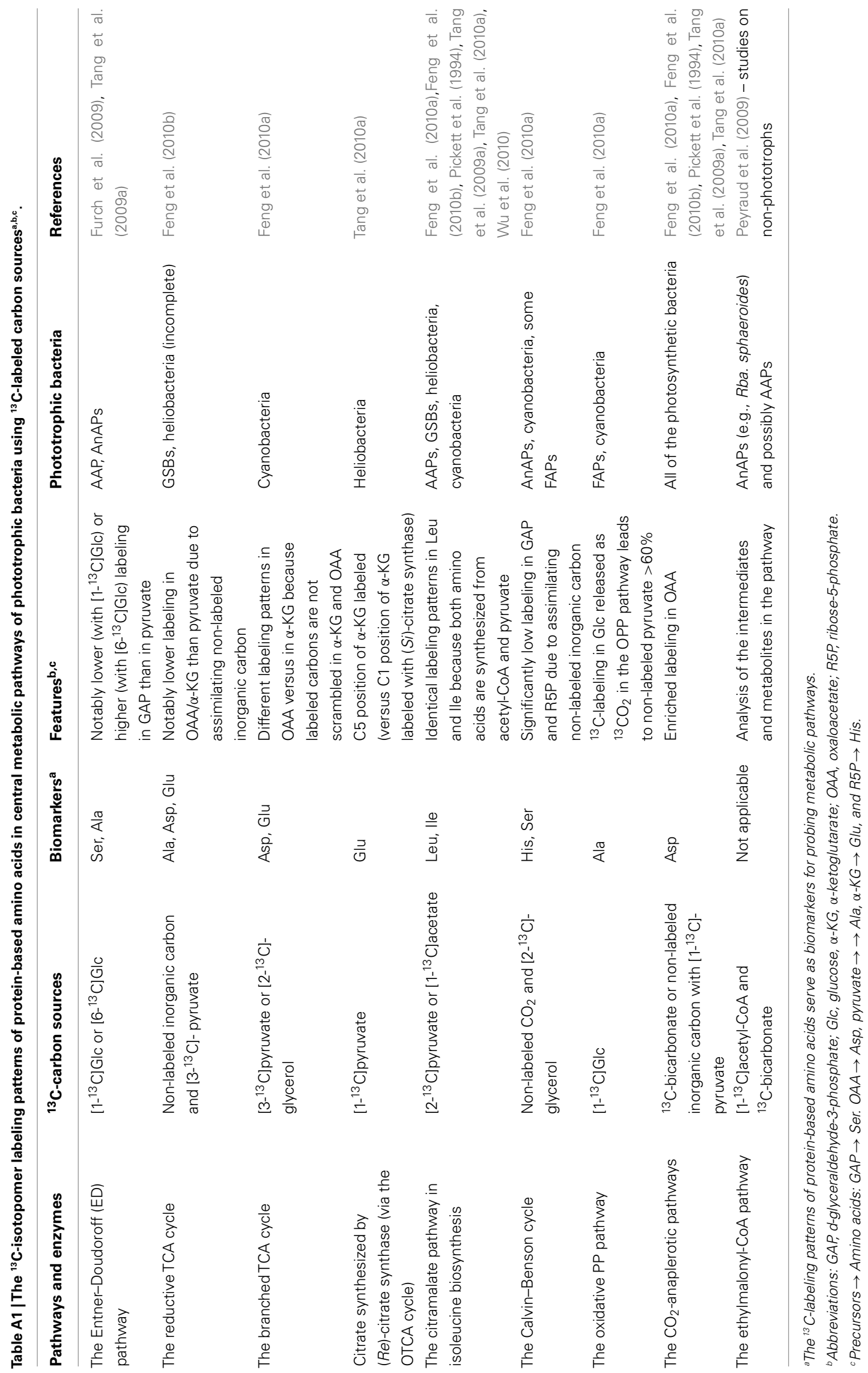




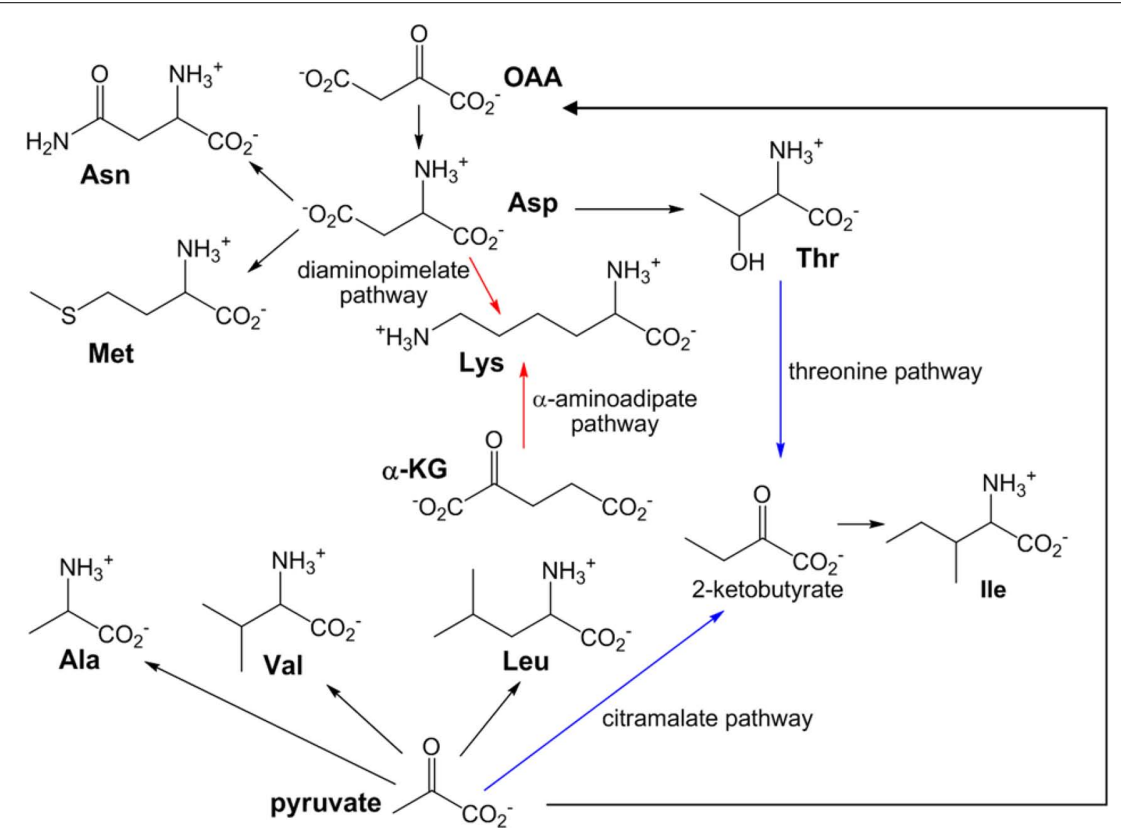

FIGURE A2 | Amino acids biosynthesis in phototrophic and

non-phototrophic bacteria. Biosynthesis of amino acids directly and

indirectly employing pyruvate and oxaloacetate (OAA) as precursors is shown.
The pathways for isoleucine and lysine biosynthesis are shown in blue and red, respectively. Phototrophic bacteria have not yet been known to synthesize lysine via the $\alpha$-aminoadipate pathway.

\section{REFERENCES}

Howell, D. M., Xu, H., and White, R. H. (1999). (R)-citramalate synthase in methanogenic archaea. J. Bacteriol. 181, 331-333.

Risso, C., Van Dien, S. J., Orloff, A., Lovley, D. R., and Coppi, M. V. (2008). Elucidation of an alternate isoleucine biosynthesis pathway in Geobacter sulfurreducens. J. Bacteriol. 190, 2266-2274.

Sanford, K., Soucaille, P., Whited, G., and Chotani, G. (2002). Genomics to fluxomics and physiomics - pathway engineering. Curr. Opin. Microbiol. 5, 318-322.

Sauer, U. (2006). Metabolic networks in motion: 13C-based flux analysis. Mol. Syst. Biol. 2, 62.

Singh, A. K., Bhattacharyya-Pakrasi, M., Elvitigala, T., Ghosh, B., Aurora, R., and Pakrasi, H. B. (2009) A systemslevel analysis of the effects of light quality on the metabolism of a cyanobacterium. Plant Physiol. 151, 1596-1608.
Stitt, M., Sulpice, R., and Keurentjes, J. (2010). Metabolic networks: how to identify key components in the regulation of metabolism and growth. Plant Physiol. 152, 428-444.

Strauss, G., Eisenreich, W., Bacher, A., and Fuchs, G. (1992) 13C-NMR study of autotrophic $\mathrm{CO} 2$ fixation pathways in the sulfur-reducing Archaebacterium Thermoproteus neutrophilus and in the phototrophic Eubacterium Chloroflexus aurantiacus. Eur. J. Biochem. 205, 853-866.
Wu, B., Zhang, B., Feng, X., Rubens, J. R., Huang, R., Hicks, L. M., Pakrasi, H. B., and Tang, Y. J. (2010). Alternative isoleucine synthesis pathway in cyanobacterial species. Microbiology 156, 596-602.

Xu, H., Zhang, Y., Guo, X., Ren, S., Staempfli, A. A., Chiao, J., Jiang, W., and Zhao, G. (2004). Isoleucine biosynthesis in Leptospira interrogans serotype lai strain 56601 proceeds via a threonine-independent pathway. J. Bacteriol. 186, 5400-5409. 